Article

\title{
G-Protein-Coupled Estrogen Receptor (GPER)-Specific Agonist G1 Induces ER Stress Leading to Cell Death in MCF-7 Cells
}

\author{
Diep-Khanh Ho Vo ${ }^{1, *(\mathbb{D})}$, Roland Hartig ${ }^{2}$, Sönke Weinert ${ }^{3}{ }^{\mathbb{D}}$, Johannes Haybaeck ${ }^{1,4,5}$ and \\ Norbert Nass $1, *(1)$ \\ 1 Department of Pathology, Otto-von-Guericke University Magdeburg, Leipziger Str. 44, D-39120 Magdeburg, \\ Germany; johannes.haybaeck@med.ovgu.de \\ 2 Institute of Molecular and Clinical Immunology, Otto-von-Guericke University Magdeburg, \\ Leipziger Str. 44, D-39120 Magdeburg, Germany; roland.hartig@med.ovgu.de \\ 3 Department of Cardiology, Medical Faculty, Otto-von-Guericke University Magdeburg, Leipziger Str. 44, \\ D-39120 Magdeburg, Germany; soenke.weinert@med.ovgu.de \\ 4 Department of Pathology, Neuropathology, and Molecular Pathology, Medical University of Innsbruck, \\ Innrain, Christoph-Probst-Platz 52, D-6020 Innsbruck, Austria \\ 5 Department of Pathology, Diagnostic \& Research Center for Molecular BioMedicine, Institute of Pathology, \\ Medical University of Graz, Auenbruggerpl. 2, D-8036 Graz, Austria \\ * Correspondence: khanh.vo@med.ovgu.de (D.-K.H.V.); norbert.nass@med.ovgu.de (N.N.); \\ Tel.: +49-391-67-17948 (D.-K.H.V.)
}

Received: 10 July 2019; Accepted: 12 September 2019; Published: 18 September 2019

check for updates

\begin{abstract}
The G-protein-coupled estrogen receptor (GPER) mediates rapid non-genomic effects of estrogen. Although GPER is able to induce proliferation, it is down-regulated in breast, ovarian and colorectal cancer. During cancer progression, high expression levels of GPER are favorable for patients' survival. The GPER-specific agonist G1 leads to an inhibition of cell proliferation and an elevated level of intracellular calcium $\left(\mathrm{Ca}^{2+}\right)$. The purpose of this study is to elucidate the mechanism of G1-induced cell death by focusing on the connection between G1-induced $\mathrm{Ca}^{2+}$ depletion and endoplasmic reticulum (ER) stress in the estrogen receptor positive breast cancer cell line MCF-7. We found that G1-induced ER Ca ${ }^{2+}$ efflux led to the activation of the unfolded protein response (UPR), indicated by the phosphorylation of IRE1 $\alpha$ and PERK and the cleavage of ATF6. The pro-survival UPR signaling was activated via up-regulation of the ER chaperon protein GRP78 and translational attenuation indicated by eIF2- $\alpha$ phosphorylation. However, the accompanying pro-death UPR signaling is profoundly activated and responsible for ER stress-induced cell death. Mechanistically, PERK-phosphorylation-induced JNK-phosphorylation and IRE1 $\alpha$-phosphorylation, which further triggered CAMKII-phosphorylation, are both implicated in G1-induced cell death. Our study indicates that loss of $\mathrm{ER} \mathrm{Ca}^{2+}$ is responsible for G1-induced cell death via the pro-death UPR signaling.
\end{abstract}

Keywords: GPER; GPER-specific agonist G1; UPR signaling; $\mathrm{Ca}^{2+}$ efflux; ER stress; JNK; CAMKII; breast cancer

\section{Introduction}

Estrogens have a multitude of cellular and physiological effects, ranging from the control of reproduction to the regulation of cell differentiation and proliferation. Besides canonical genomic signaling via nuclear estrogen receptors [1], there are signaling pathways comprising membrane bound estrogen receptors such as the G-protein-coupled estrogen receptor (GPER), formerly named 
GPR30 [2-4]. GPER mediates the rapid non-genomic effects of estrogen, including the production of cyclic adenosine monophosphate (cAMP), the mobilization of intracellular calcium $\left(\mathrm{Ca}^{2+}\right)$, transactivation of epidermal growth factor receptor (EGFR) and the activation of multiple kinases, such as phosphoinositide 3-kinase/protein kinase B (PI3K/AKT) and ERK1/2 mitogen activated-protein kinases (MAPK) [5], often resulting in increased proliferation. GPER is located not only on the plasma membrane but also on the membrane of the endoplasmic reticulum (ER) [4], and is found to be ubiquitously expressed in the body $[5,6]$.

From a clinical point of view, GPER is downregulated with breast cancer (BC) tumor progression and a high expression correlates with favorable patient survival [7-10]. A similar observation was also reported for ovarian [11] and colorectal cancer (CRC) [12]. Nevertheless, high GPER expression also correlated with the development of distant metastasis in BC [13]. In case of BC anti-estrogen therapy, high GPER levels were associated with a shorter disease-free survival under tamoxifen when compared to those receiving aromatase inhibitors [14]. These conflicting observations are in line with the idea that non-specific GPER agonists, such as estrogen and tamoxifen, induce cell proliferation by GPER stimulation, thereby replacing the tamoxifen-blocked genomic estrogen signaling and activating a cross talk of GPER with growth factor signaling [15,16].

Nonsteroidal, high-affinity, highly selective agonists of GPER, such as G1, have been developed from a library of 10,000 molecules [17]. G1 selectively activates GPER but not the classical estrogen receptors. Moreover, previous reports showed that G1 profoundly inhibited cell proliferation and induced apoptosis in BC, prostate cancer and CRC cell lines [12,18-22], potentially via p53 and p21 induction [19,23]. G1-mediated GPER activation also elicited cytosolic $\mathrm{Ca}^{2+}$ currents in BC cell lines [18]. Decreasing GPER abundance by siRNA inhibited both the upregulation of the L-type $\mathrm{Ca}^{2+}$ channel subunit $\alpha 1 \mathrm{D}$ named Cav1.3, and the $17 \beta$-estradiol $\left(\mathrm{E}_{2}\right)$-induced $\mathrm{Ca}^{2+}$ influx. The inhibition of Cav1.3 by siRNA suppressed $\mathrm{E}_{2}$-induced intracellular $\mathrm{Ca}^{2+}$ upregulation and cell proliferation [24]. However, little is known about the precise apoptotic mechanism following the mobilization of intracellular $\mathrm{Ca}^{2+}$ induced by GPER-specific agonist G1 in BC. In vivo, G1 inhibited tumor growth in estrogen receptor (-) BC cells [23] and HCT116 CRC tumor xenografts in mice [12]. These studies suggest that GPER can serve as a potential therapeutic target in $\mathrm{BC}$.

$\mathrm{Ca}^{2+}$ homeostasis is important for the functioning of ER as ER-resident chaperones, such as calreticulin and glucose-regulated protein 78 (GRP78), which need a high concentration of $\mathrm{Ca}^{2+}$ for their activity [25]. If ER $\mathrm{Ca}^{2+}$ homeostasis is lost, the unfolded protein response (UPR) will be activated, either re-establishing the ER functions or triggering cell death. The UPR is mediated by three major signaling proteins, inositol-requiring enzyme $1 \alpha$ (IRE1 $\alpha)$, protein kinase R-like ER kinase (PERK, EIF2AK3) and activating transcription factor 6 (ATF6) [26]. If $\mathrm{ER} \mathrm{Ca}^{2+}$ is severely decreased, ER stress-induced cell death will be promoted by either affecting mitochondrial $\mathrm{Ca}^{2+}$ via causing mitochondrial outer membrane permeabilization or by the loss of the mitochondrial transmembrane potential $(\Delta \Psi \mathrm{m})$ [27], or by activating the pro-death UPR signaling. These events can directly release cytochrome $\mathrm{c}$ to the cytosol to induce apoptosis.

Mechanistically, ER stress stimulates the autophosphorylation of the IRE1 $\alpha$ cytosolic domain to become an active endoribonuclease (RNAse) cleaving an intron of X-box binding protein 1 (XBP1) mRNA, resulting in the translation of bZIP-containing transcription factor XBP1s [28]. XBP1s activates the adaptive response by inducing the transcription of genes to assist ER stress. Activated IRE1 $\alpha$ also causes phosphorylation of Jun-N-terminal kinase (JNK) and p38-MAPK to promote apoptosis [29]. On activation, autophosphorylated PERK can either induce pro-survival or pro-apoptotic signaling. Activated PERK catalyzes the phosphorylation of eukaryotic translation initiator factor $2 \alpha$ (eIF2 $\alpha$ ) to attenuate protein biosynthesis. In addition, phosphorylation of eIF $2 \alpha$ also induces the translation of activating transcription factor 4 (ATF4) [26]. On activation by the binding of GRP78, ATF6 translocates to the Golgi apparatus, where it is cleaved to become an active transcription factor and to further activate transcription of target genes such as ER chaperones [26]. Both ATF6 and ATF4 also control the expression of pro-apoptotic proteins, including C/EBP-homologous protein (CHOP) [26]. p38 is 
also reported to activate CHOP, in turn causing changes in gene expression that favor apoptosis [30]. Therefore, CHOP is regarded as one of the most important mediators of ER stress-induced apoptosis [31].

The approach of $\mathrm{Ca}^{2+}$ depletion-induced ER stress leading to cell death has been used to develop new chemotherapies, for example thapsigargin and curcumin, two well-known sarco/ER Ca ${ }^{2+}$-ATPase (SERCA) blockers [32,33]. In the present study, we investigated the precise connection between GPER activation by G1 and ER stress causing cell death in the estrogen receptor-positive BC cell line MCF-7. We found that G1-induced $\mathrm{Ca}^{2+}$ efflux activates the UPR; however, up-regulation of CHOP or the mitochondrial transmembrane potential is not involved in G1-induced cell death. We further demonstrate that the phosphorylation of PERK, which directly induces the activation of JNK kinase, is implicated in G1-induced cell death. Moreover, the phosphorylation of IRE1 $\alpha$ does not cleave XBP1 but directly activates calcium/calmodulin-dependent protein kinase II (CaMKII), causing G1-induced cell death. We conclude that G1 triggers a mobilization of ER $\mathrm{Ca}^{2+}$ stores, leading to UPR activation. The accompanying pro-death UPR signaling is then responsible for G1-induced cell death

\section{Materials and Methods}

\subsection{Reagents}

G1 was purchased from Tocris (Wiesbaden-Nordenstadt, Germany), dissolved (5 mM) in dimethyl sulfoxide (DMSO) (Roth, Karsruhe, Germany) and stored at $-20{ }^{\circ} \mathrm{C}$; Thapsigargin, SP600125, GSK2606414 were also purchased from Tocris. Indo-1 AM was from Thermo Fisher Scientific (Waltham, MA, USA). zVAD-fmk was bought from Santa Cruz (Santa Cruz, CA, USA). SB203580 and Kira6 were purchased from MERCK Millipore (Darmstadt, Germany). All substances were dissolved in DMSO. Antibodies were obtained from the following commercial sources: caspase 9 (Ca\# 9502), cleaved PARP (Ca\# 9541), IRE1 $\alpha$ (Cat\# 3294), PERK (Cat\# 3192), eIF2 $\alpha$ (Cat\# 5234), phospho-eIF2 $\alpha$ (Cat\# 3398), BiP GRP78 (Ca\# 3177), CHOP (Cat\# 2895), p38 MAPK (Ca\# 9212), phospho-p38 MAPK (Ca\# 4511), phospho-SAPK/JNK (Ca\# 4668), caspase 3 (Ca\# 9662), BCL-2 (Ca\# 2872), Cell Signaling (Danvers, MA, USA); ATF6 (Cat\# 73500), BioAcademia (Osaka, Japan); puromycin (Ca\# MABE343), cylophilin D (Ca\# AP1035), MERCK Millipore (Darmstadt, Germany); phospho-IRE1 $\alpha$ (Cat\# NBP2-50067), Novus Biologicals (Littleton, CO, USA); cytochrome c (Ca\# 556433), BD Biosciences (Franklin Lakes, NJ, USA); $\beta$-actin (Cat\# A5441, Sigma-Aldrich (Steinheim, Germany)). Secondary, peroxidase-conjugated antibodies were purchased from Dianova (Hamburg, Germany). All other chemicals of analytical grade were obtained from Sigma-Aldrich or Roth.

\subsection{Cell Lines and Cell Culture}

MCF-7 cells were obtained from the American Type Culture Collection (ATCC, HTB-22) (Manassas, VA, USA). Cells were routinely maintained in phenol-red-free RPMI 1640, which contained 10\% fetal bovine serum (FBS) and $200 \mu \mathrm{M}$ L-glutamax (all from Biochrom, Berlin, Germany). Cells were grown at $37{ }^{\circ} \mathrm{C}$ in an atmosphere of $95 \%$ air and $5 \% \mathrm{CO}_{2}$ and transferred into new flasks (Nunc) after detachment with Trypsin/EDTA (Biochrom).

\subsection{Cell Treatment}

To elucidate the mechanism of cell death induced by GPER-specific agonist G1 via ER stress, MCF-7 cells were treated with 1,2.5 and $5 \mu \mathrm{M}$ G1 for the indicated period in growth medium containing FBS. As positive controls, cells were also exposed to $1 \mu \mathrm{M}$ thapsigargin for the indicated time. DMSO was used as a vehicle for control treatments. To evaluate the effect of pan caspases inhibitor zVAD-fmk, cells were pretreated with $20 \mu \mathrm{M} z V A D$ for $1 \mathrm{~h}$ before further treatment. Cells were also pretreated with a variable concentration of kinase inhibitors SB203580, SP60025, GSK2606414 and Kira6 for $1 \mathrm{~h}$ before further treatment. 


\subsection{Cell Cycle and Apoptosis Analysis by Flow Cytometry}

MCF-7 cells were collected 24, 48 and $72 \mathrm{~h}$ after treatment. For cell cycle analysis, cells were fixed with $70 \%$ ethanol, treated with $1 \%$ RNase in TE buffer and finally stained with a hypotonic propidium iodide (PI) solution (50 $\mathrm{g} / \mathrm{mL}$ in PBS). Cell cycle analysis was performed using a flow cytometer (LSRFortessa, BD Bioscience, San Jose, CA, USA). Cell cycle distribution (percentage of cells) in cell debris (sub-G1) and G1, S, and G2/M phases of the cell cycle was analyzed using FlowJo software version 7.6 (Treestar, Ashland, OR, USA). To discriminate between apoptosis and necrosis, cells were detached with Trypsin/EDTA and stained with FITC Annexin V (BioLegend, San Diego, CA, USA) and PI (50 $\mu \mathrm{g} / \mathrm{mL})$. Then, necrotic and apoptotic cells were determined using a flow cytometer (LSRFortessa). Data were analyzed using FlowJo software version 7.6 (Treestar, Ashland, OR).

\subsection{Immunoblotting}

A whole cell extract was prepared as described previously [34]. Briefly, cells were suspended in a lysis buffer (150 mM NaCl, 50 mM Tris- $\mathrm{HCl}$ (pH 7.5), 1\% NP-40, 1\% sodium deoxycholate, 0.1\% SDS) containing phosphatase and protease inhibitor cocktails (MERCK Millipore, Darmstadt, Germany) on ice for $30 \mathrm{~min}$. Cellular debris was removed by centrifugation for $15 \mathrm{~min}$ at $12,000 \times g$ and $4{ }^{\circ} \mathrm{C}$. Protein content was determined by the BCA reagent (Thermo Fisher Scientific (Waltham, MA, USA)), and equal amounts were subjected to denaturing SDS-PAGE. Blotting was performed with a BioRad semi-dry blotting chamber using a nitro cellulose membrane (GE Healthcare, Chicago, Illinois, USA) for $1 \mathrm{~h}$ at $1 \mathrm{~mA}$ per $\mathrm{cm}^{2}$ in CAPS buffer (CAPS $50 \mathrm{mM} \mathrm{pH} \mathrm{10,} \mathrm{methanol} \mathrm{10 \%} \mathrm{and} \beta$-mercapto-propionic acid $1 \mathrm{mM}$ ). Transfer to the membrane was controlled by Ponceau red staining, and the membrane was blocked with $2 \%$ BSA or 5\% skim milk in TBS (Tris/Cl $50 \mathrm{mM} \mathrm{pH} \mathrm{7.4,} \mathrm{NaCl} 150 \mathrm{mM}, 0.2 \%$ NP40). Immunoblotting with appropriate antibodies was visualized with an enhanced chemiluminescence reagent (MERCK Millipore, Darmstadt, Germany) in an INTAS chemstar imager (Intas, Goettingen, Germany).

\subsection{Indo-1 AM Staining}

To measure cytosolic $\mathrm{Ca}^{2+}$, MCF-7 cells were stained with $1 \mu \mathrm{M}$ Indo-1-AM (Thermo Fisher Scientific) in RPMI1640 medium (phenol-red free) containing $10 \%$ FBS at $37{ }^{\circ} \mathrm{C}$ for 45 min. Then, cells were washed and incubated for another $45 \mathrm{~min}$ at $37{ }^{\circ} \mathrm{C}$ in RPMI 1640 containing $10 \%$ FBS. After washing, the samples were analyzed using a flow cytometer (LSR I BD Bioscience, Heidelberg, Germany). Cells were illuminated with the $325 \mathrm{~nm}$ laser line of a helium-cadmium laser. Flourescence emissions at 390 to $420 \mathrm{~nm}$ and 500 to $520 \mathrm{~nm}$ were detected simultaneously, and changes in the ratio of the two emission intensities were analyzed with FLowJo software. To demonstrate successful loading with the dye, we induced maximal $\mathrm{Ca}^{2+}$ release by adding calcium ionophore ionomycin $(10 \mathrm{mg} / \mathrm{mL})$ (Sigma-Aldrich). $\mathrm{Ca}^{2+}$ efflux in MCF-7 cells was performed in response to varying concentrations of G1 or TG. DMSO was used as a negative control.

\subsection{Measurement of Protein Synthesis by the Surface Sensing of Translation (SUnSET) Puromycin End-Labeling Assay}

At the end of a treatment, cells were incubated with $10 \mu \mathrm{g} / \mathrm{mL}$ puromycin for 15 min prior to cell lysis. Whole cell lysates were then subjected to immunoblotting. Anti-puromycin antibody was used to detect the level of puromycin-labeled proteins by Western blotting as described above.

\subsection{Real-Time PCR}

To determine CHOP mRNA levels, quantitative RT-PCR was carried out. RNA isolation, cDNA synthesis and quantitative (Q) PCR were performed as follows: The RNA isolation kit was purchased from Macherey and Nagel, (Düren, Germany). Briefly, $1 \mu \mathrm{g}$ total RNA was used for each cDNA synthesis by using BioScript Reverse Transcriptase (Bioline, Germany) using oligo dT primers (Promega, 
Madison, Wisconsin, USA) and random hexamer primers (Promega) separately. Both reactions were then pooled and used for qPCR. The PCR reaction was monitored in a Roche light cycler 2.0 by using the SYBR Green I Master (Roche, Mannheim, Germany) added to the PCR reaction mix. The relative mRNA level of $C H O P$ was calculated by the $2^{-\Delta \Delta C t}$ method using human RPL13A as the reference gene for normalization. The following primers (Biomers, Germany) were used: human $C H O P$ forward, 5'-agtctaaggcactgagcgta-3'; reverse, 5'-ttgaacactctctcctcaggt-3'; human RPL13A forward, $5^{\prime}$-cctggaggagaagaggaaagaga- $3^{\prime}$; reverse, $5^{\prime}$-ttgaggacctcttgtgtatttgtcaa- $3^{\prime}$.

\subsection{Knockdown of CHOP by Small Interfering RNA}

ON-TARGETplus DDIT3 (CHOP) siRNA was obtained from GE-Dharmacon (Colorado, USA). ON-TARGETplus Non-targeting Control Pool (GE-Dharmacon) was used as negative control for RNAi experiments. The siRNA was transfected into MCF-7 cells at a final concentration of $25 \mathrm{nM}$ siRNA by Dharmafect 2 transfection reagent (GE-Dharmacon) for $24 \mathrm{~h}$ before further experiments. To confirm the knockdown efficiency for CHOP, mRNA expression and protein content were analyzed by qPCR and immunoblotting.

\subsection{Determination of Cell Viability}

For determination of cell viability, the lactate dehydrogenase (LDH) assay or resazurin assay was used. The LDH activity assay was performed as described previously [34]. Data were expressed as the percentage of total LDH activity, after subtraction of the background determined from the unused culture medium alone. Alternatively, resazurin $(10 \mu \mathrm{g} / \mathrm{mL})$ was added to the cell culture medium and incubated for 30 to $120 \mathrm{~min}$ at $37^{\circ} \mathrm{C}$. Then $100 \mu \mathrm{L}$ resazurin solution was sampled and fluorescence recorded at wavelengths of 525/580-640 $\mathrm{nm}$ in a CLARIOstar microplate reader (BMG LabTech, Ortenberg, Germany).

\subsection{Mitochondrial Potential Measurement}

To measure the mitochondrial membrane potential $(\Delta \Psi \mathrm{m}), \mathrm{MCF}-7$ cells were stained with $10 \mathrm{nM}$ tetramethylrhodamine ethyl ester (TMRE) (BD Pharmingen, San Diego, CA, USA)) in RPMI1640 medium (phenol-red free) containing $10 \%$ FCS at $37^{\circ} \mathrm{C}$ for $15 \mathrm{~min}$. MitoStatus TMRE is a fluorescent dye that is readily sequestered by active mitochondria, allowing flow cytometric or imaging analysis to assess apoptosis or mitochondrial depolarization. Then, cells were washed 2 times with cold RPMI medium. After washing, the samples were analyzed using a flow cytometer (LSRFortessa). Values of $\Delta \psi \mathrm{m}$ were analyzed using FlowJo software. $\Delta \psi \mathrm{m}$ was determined in response to $1 \mu \mathrm{M}$ G1 or TG at 3 , $5,8,16$ and $24 \mathrm{~h}$. DMSO was used as a negative control. Carbonyl cyanide $m$-chlorophenyl hydrazone (CCCP) was used as a positive control. It induces the opening of the permeability transition pore on the mitochondrial membrane, leading to the dissipation of $\Delta \Psi \mathrm{m}$.

\subsection{Subcellular Fractionation}

Cells were collected by gentle scratching in a $200 \mu \mathrm{L}$ digitonin buffer $(150 \mathrm{mM} \mathrm{NaCl}, 10 \mathrm{mM}$ Tris- $\mathrm{HCl}$ ( $\mathrm{pH} 7.4), 40 \mu \mathrm{g} / \mathrm{mL}$ digitonin (Roth, Karlsruhe, Germany)). After $10 \mathrm{~min}$ incubation on ice, the cell suspension was centrifuged at $8000 \times g$ for $5 \mathrm{~min}$ at $4{ }^{\circ} \mathrm{C}$. The resulting supernatant was kept as a cytosolic-enriched digitonin extract. The resulting pellet was resuspended by vortexing in $200 \mu \mathrm{L}$ NP-40 buffer ( $150 \mathrm{mM} \mathrm{NaCl}, 10 \mathrm{mM}$ Tris- $\mathrm{HCl}$ (pH 7.4), 1\% NP-40). After $30 \mathrm{~min}$ of incubation on ice, the cell pellet was centrifuged at $13,000 \times g$ for 5 min at $4{ }^{\circ} \mathrm{C}$. The resulting supernatant was kept as a membrane organellar protein-enriched NP-40 extract. Equal aliquots from each fraction were analyzed for immunoblotting. 


\subsection{Statistical Analysis}

Data are reported as mean \pm SD of at least three independent experiments unless otherwise indicated. The statistical significance of the difference between the determinations was calculated by analysis of variance using ANOVA, a Tukey-Kramer multiple comparisons test or a Student's $t$ test. The difference was considered as significant when the $p$ value was $<0.05$ or $<0.01$.

\section{Results}

\subsection{G1 and TG Induced Cell Cycle Arrest in G2/M and Apoptosis without Activating Caspase-3 and 9 in} MCF-7 Cells

G1 was proposed to induce apoptosis in MCF-7 cells, but the detailed mechanism remains elusive $[18,22]$. We analyzed this process further to better understand the molecular pathway leading to G1-induced cell death.

MCF-7 cells were treated with $1 \mu \mathrm{M}$ G1 or $1 \mu \mathrm{M}$ G1 thapsigargin (TG), a procedure that was reported to induce apoptosis in MCF-7 cells [35]. Cell cycle and apoptosis were re-evaluated after 24, 48 and $72 \mathrm{~h}$ by flow cytometry. Our results showed that G1 inhibited proliferation of MCF-7 cells by a remarkable arrest in G2/M already $24 \mathrm{~h}$ after stimulation compared to the control group (Figure 1a). This block was associated with a concomitant decrease in the percentage of cells in the G1 phase, and a smaller reduction in the $S$ phase. This effect was also evident after 48 and $72 \mathrm{~h}$ of G1 treatment. TG stimulation showed a decrease in cells in the $S$ phase after $24 \mathrm{~h}$ and in the G2/M checkpoint after $48 \mathrm{~h}$ (Figure 1a). These results indicate that the stimulation of GPER by G1 prevents cells from entering both the synthesis phase and the mitotic phase, thereby causing an inhibition of cell proliferation of $\mathrm{BC}$ MCF-7 cells.

Next, we re-investigated the characteristics of apoptosis in MCF-7 cells induced by G1. After treatment, cells were stained with Annexin V and propidium iodide (PI), and apoptotic cells were determined by flow cytometry. Both G1 and TG treatment led to early apoptosis in a small number of cells, while about $10 \%$ of the cells showed signs of late apoptosis after $24 \mathrm{~h}$. This amount of late apoptotic cells was further increased at $48 \mathrm{~h}$ and remained constant at about $18 \%$ at $72 \mathrm{~h}$ compared to the control group (Figure $1 \mathrm{~b}, \mathrm{c}$ ), indicating a constant rate of apoptosis after $48 \mathrm{~h}$ resulting in increasing numbers of dead detached cells. Notably, expression of caspase 3 is completely absent in MCF-7 cells compared to SK-BR-3 and MDA-MB-231 cell lines (Figure S1). We observed the cleavage of PARP but not of caspase 9 after $24 \mathrm{~h}$ stimulation by G1 and TG in all concentrations tested: 1, 2.5 and $5 \mu \mathrm{M}$ compared to the DMSO treatment (Figure 1d). Western Blot (WB) revealed similar results after 48 and $72 \mathrm{~h}$ treatment. Then, we examined the effect of the pan-caspase inhibitor zVAD-fmk (zVAD) on G1- and TG-induced apoptosis in MCF-7 cells. WB analysis showed that the cleavage of PARP was inhibited in the presence of zVAD compared to the control cells (Figure 1d). Due to the intracellular release of toxic fluoroacetate [36], zVAD-fmk could not significantly prevent G1-induced apoptosis (data not shown). Taken together, these results confirm that after $24 \mathrm{~h}$ stimulation, GPER-specific agonist G1 induces cell cycle arrest at G2/M and late apoptosis although caspases 3 and 9 are not involved in the mechanism. 
A
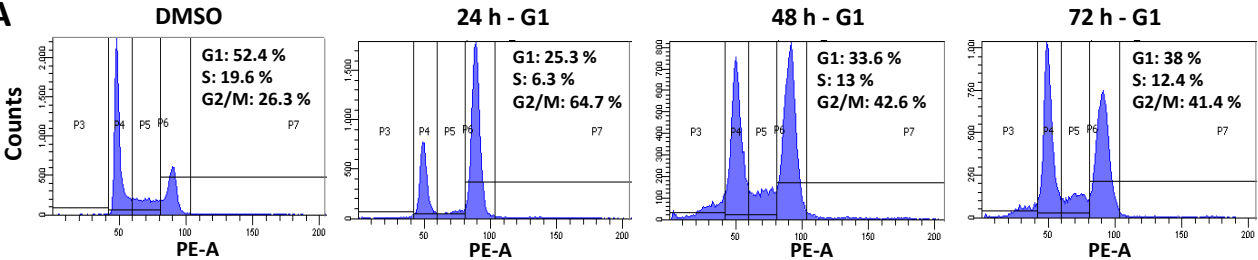

$24 \mathrm{~h}$ - TG

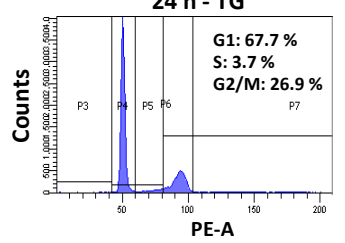

$48 \mathrm{~h}$ - TG

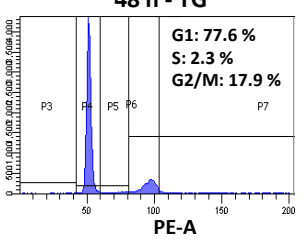

B

B
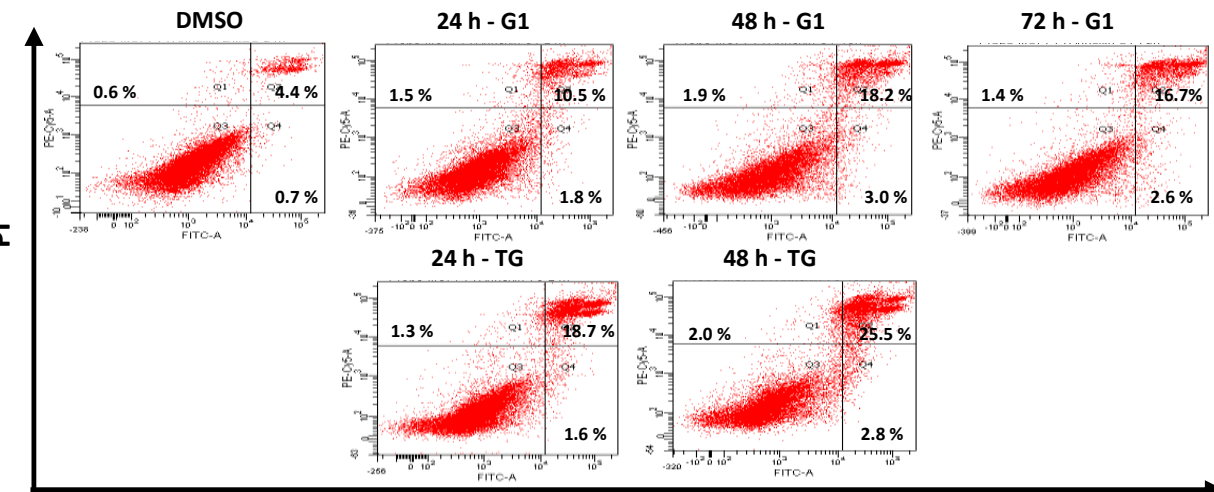

Annexin V-positive cells (\%)
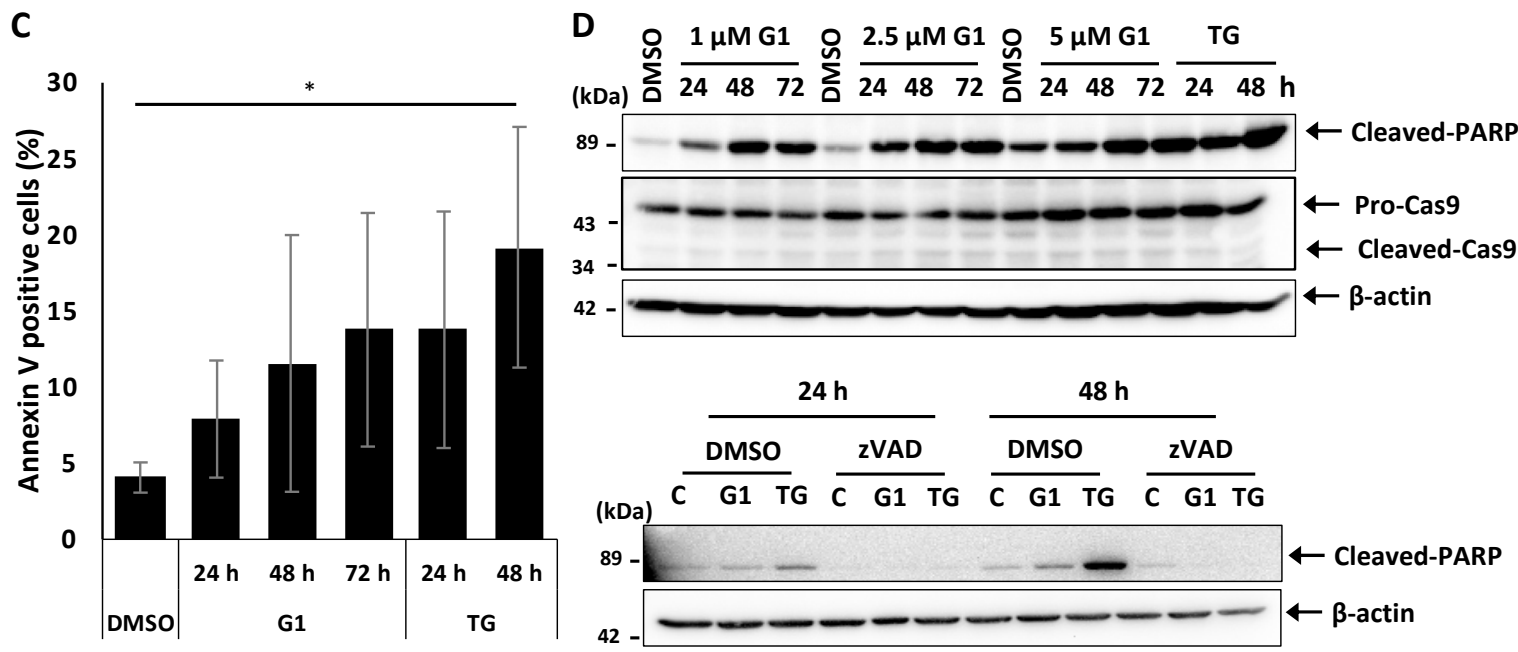

Figure 1. G1 and TG induced cell cycle arrest in G2/M and apoptosis without activating caspase 3 and 9 in MCF-7 cells. MCF-7 cells were treated with $1 \mu \mathrm{M} \mathrm{G1}$ for 24,48 and $72 \mathrm{~h}$ or with $1 \mu \mathrm{M}$ TG for 24 and $48 \mathrm{~h}$. (A) Cells were stained with propidium iodide (PI), and cell cycle profiles were determined by flow cytometry analysis. The percentage of cells in the different cell cycle phase was calculated. (B,C) Cells were double stained with PI and Annexin V. Flow cytometry analysis was performed to determine apoptotic and necrotic cells. Representative dot plots and percentage in each quadrant showed cell death undergoing necrosis (Q1), apoptosis (Q4) or late apoptosis (Q2). ${ }^{*} p<0.05$ when compared with cells treated with vehicle. (D) MCF-7 cells were treated with 1, 2.5 and $5 \mu \mathrm{M} \mathrm{G1}$ for 24, 48 and $72 \mathrm{~h}$, or with $1 \mu \mathrm{M}$ TG for 24 and $48 \mathrm{~h}$, or pretreated with $20 \mu \mathrm{M}$ pan caspases inhibitor zVAD-fmk for $1 \mathrm{~h}$ and then treated with $1 \mu \mathrm{M}$ G1 or TG for 24 and $48 \mathrm{~h}$. Total protein lysates were subjected to Western blotting using appropriate antibodies as indicated. 


\subsection{G1 and TG Induced $\mathrm{Ca}^{2+}$ Efflux and Activated the UPR in MCF-7 Cells}

As previous studies have shown that G1 resulted in $\mathrm{Ca}^{2+}$ mobilization from the ER [18], we hypothesized that loss of $\mathrm{Ca}^{2+}$ of the ER could contribute to the cell death mechanism. As a first step in investigating this process further, we re-investigated this effect by using the Indo- 1 dye as indicator to analyze the intracellular $\mathrm{Ca}^{2+}$ concentration. Figure $2 \mathrm{a}$ revealed an elevation of $\mathrm{Ca}^{2+}$ concentration in the cytosol with $\mathrm{G} 1$ concentrations at $0.5,1$ and $5 \mu \mathrm{M}$ compared to the DMSO treatment. A similar but much stronger and faster increase of $\mathrm{Ca}^{2+}$ efflux from the ER was detected in TG-stimulated MCF-7 cells (Figure 2b). TG is a well-established ER stress inducer known to inhibit ER $\mathrm{Ca}^{2+}$-ATPase. We also blocked extracellular $\mathrm{Ca}^{2+}$ influx by using EGTA, a chelating agent that has a high affinity to $\mathrm{Ca}^{2+}$. EGTA showed no effects on the increase in $\mathrm{Ca}^{2+}$ influx (data not shown), indicating that the mobilization of $\mathrm{Ca}^{2+}$ induced by $\mathrm{G} 1$ comes from intracellular sources, presumably the ER. The results of previous and our own research led us to conclude that stimulation by G1 leads to a rapid $\mathrm{Ca}^{2+}$ mobilization from the ER to the cytosol, and this could play an important role in G1-induced cell death.

The loss of $\mathrm{Ca}^{2+}$ from the ER led us to hypothesize that ER stress might be induced by and involved in the mechanism of G1-induced MCF-7 cell death. Therefore, we examined the activation of the UPR by immunoblotting. The phosphorylation of IRE1 $\alpha$ was induced by all G1 concentrations $(1,2.5$ and $5 \mu \mathrm{M}$ ) tested after 24, 48 and $72 \mathrm{~h}$ treatment (Figure 2c). The same result was observed in cells treated with $1 \mu \mathrm{M}$ TG for 24 and $48 \mathrm{~h}$. However, G1-induced IRE1 $\alpha$ phosphorylation could not induce XBP1 splicing (XBP1s) compared to TG-activated IRE1 $\alpha$ phosphorylation (Figure 2c). Moreover, G1 and TG promoted the reduction of full-length ATF6 in an equivalent experimental setting as compared with DMSO-treated MCF-7 cells (Figure 2c). The phosphorylation of PERK was also induced in cells treated with all G1 concentrations tested. This became evident in the form of a mobility shift of PERK bands on SDS-PAGE as compared with the control cells (Figure 2c). The same band shifts were observed in cells treated with $1 \mu \mathrm{M}$ TG. We also found that the expression of ER-resident proteins, such as GRP78, was elevated in G1 and TG-treated cells as compared with the control group (Figure 2c). Altogether, our findings indicate that the UPR is indeed activated, and ER stress occurs upon GPER stimulation by G1.

We further found that the phosphorylation of eIF2 $\alpha$ was induced in both G1 and TG treatment as compared with DMSO treatment in MCF-7 cells. Using SUnSET, a non-radioactive system monitoring newly synthesized proteins based on probing puromycin-labeled proteins [28,37], we observed a decrease in puromycin-labeled proteins in the cells treated with $1 \mu \mathrm{M}$ of $\mathrm{G} 1$ for 24,48 and $72 \mathrm{~h}$ as compared with the control group (Figure 2d). These results suggest that stimulation of GPER by its specific agonist G1 also inhibits global protein synthesis via the phosphorylation of eIF2 $\alpha$ in MCF-7 cells.

We then hypothesized that increased $\mathrm{Ca}^{2+}$ concentration in the cytosol due to GPER stimulation by G1 could lead to a functional loss of the mitochondrial potential, resulting in apoptosis. To elucidate this hypothesis, we stained MCF-7 cells with tetramethylrhodamine ethyl ester (TMRE), which is a positively charged dye that binds to internal negative charges of the mitochondrial inner membrane. The intensity of TMRE staining of the cells represents the mitochondrial transmembrane potential $(\triangle \Psi \mathrm{m})$. Carbonyl cyanide $\mathrm{m}$-chlorophenyl hydrazone (CCCP) was used as a positive control as it induces the opening of the permeability transition pore on the mitochondrial membrane, leading to the dissipation of $\Delta \Psi \mathrm{m}$ [38]. However, in our experiments, $\Delta \Psi \mathrm{m}$ was not affected by $\mathrm{G} 1 \mathrm{nor}$ the solvent-control (DMSO) (Figure S2a), whereas CCCP decreased the $\triangle \Psi \mathrm{m}$ level, indicating mitochondrial functional loss. During apoptosis, cytochrome c is released from the intermembrane compartment of mitochondria to the cytosol to activate pro-caspase 9 . Because pro-caspase 9 was not activated in G1- and TG-treated cells (Figure 1d), we hypothesized that cytochrome c was not released by G1 and TG either. To clarify this, we performed crude subcellular fractionation to sequentially enrich cytosolic proteins in a digitonin-soluble fraction and membrane-bound organelles in a subsequent NP-40-soluble fraction. Staurosporine (STS) was used as a positive control to release cytochrome c from mitochondria to cytosol (Figure S2b). The results showed that the abundance of cytochrome c was not released from the NP-40 organellar fraction into the digitonin cytosolic fraction in both 
G1- and TG-treated cells (Figure S2b). Nevertheless, such a release was evident in STS treated cells. However, the cytosolic house-keeping protein $\beta$-actin was also found in the digitonin extract under all treatments, indicating a contamination of this fraction by cytosolic proteins. These results suggest that the mitochondrial transmembrane potential is not affected and cytochrome $\mathrm{c}$ is not released upon G1-induced ER Ca ${ }^{2+}$ mobilization.
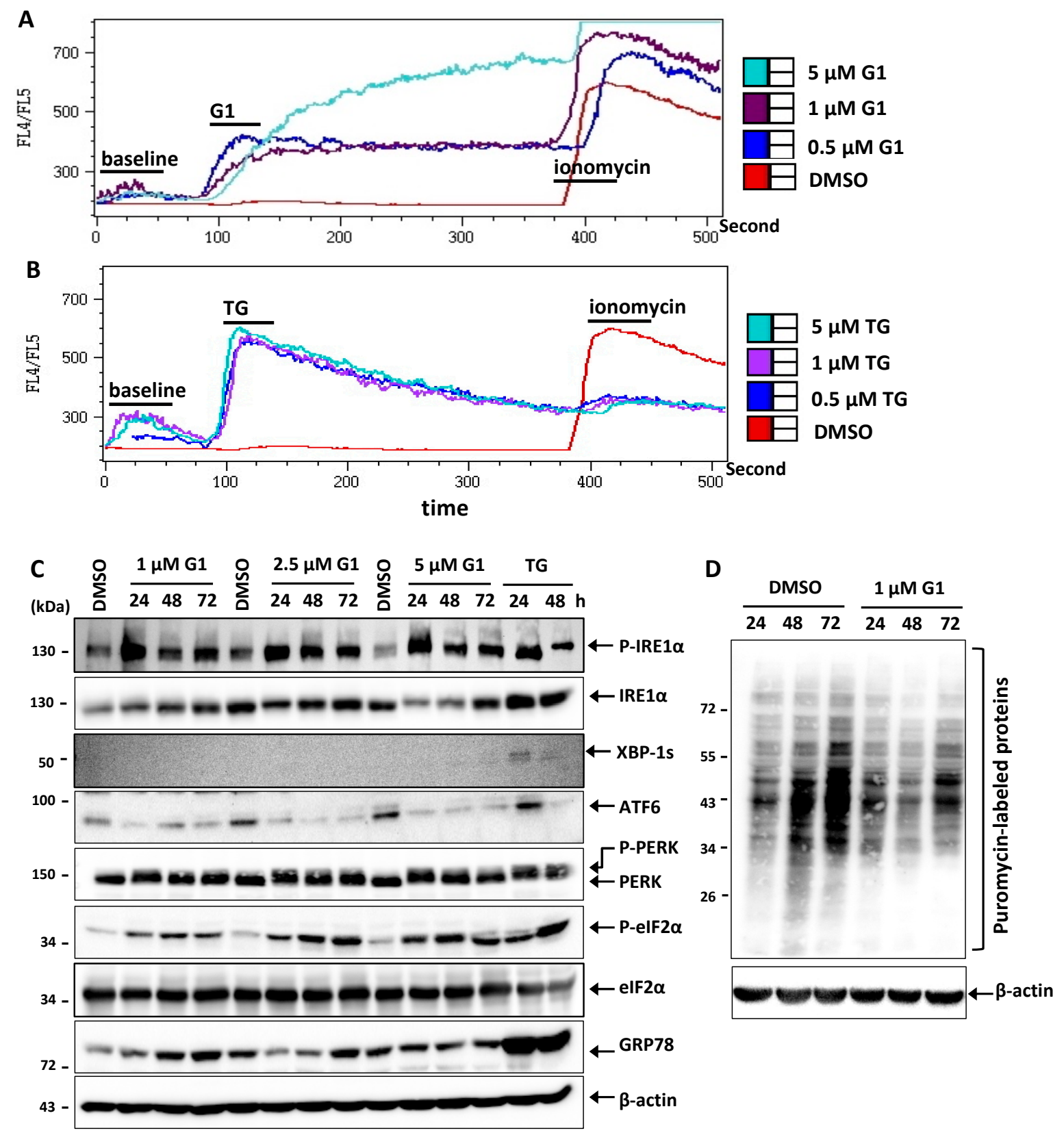

Figure 2. G1 and TG induced $\mathrm{Ca}^{2+}$ efflux and activated the UPR in MCF-7 cells. (A,B) Intracellular $\mathrm{Ca}^{2+}$ concentration was measured by flow cytometry in Indo-1-stained MCF-7 cells after stimulation with different concentrations of G1 or TG. To demonstrate successful loading with the dye, we induced maximal $\mathrm{Ca}^{2+}$ release by adding calcium ionophore ionomycin $(10 \mathrm{mg} / \mathrm{mL})$ at the end of a measurement. (C) MCF-7 cells were treated with 1, 2.5 and $5 \mu \mathrm{M} \mathrm{G1}$ for 24,48 and $72 \mathrm{~h}$, or with $1 \mu \mathrm{M}$ TG for 24 and $48 \mathrm{~h}$. (D) MCF-7 cells were treated with $1 \mu \mathrm{M} \mathrm{G} 1$ for 24,48 and $72 \mathrm{~h}$. A total of $15 \mathrm{~min}$ before the end of a treatment time, $10 \mu \mathrm{g} / \mathrm{mL}$ puromycin was added. Total protein lysates were subjected to Western blotting using appropriate antibodies as indicated. 


\subsection{Up-Regulation of CHOP Expression Was Not Involved in G1-Induced Cell Death in MCF-7 Cells}

To investigate whether G1-induced UPR activated downstream pro-death signaling, we studied the involvement of CHOP. The mRNA and protein levels of CHOP were increased by G1 typically after 48 and $72 \mathrm{~h}$ treatment compared to the control group (Figure $3 \mathrm{a}, \mathrm{b}$ ). Similar results were observed in TG-treated cells (Figure 3b). siRNA-mediated reduction of CHOP could inhibit the expression of CHOP induced by G1 and TG but not the cleavage of PARP (Figure 3c). CHOP siRNA also failed to prevent cell death induced by G1 and TG in MCF-7 cells (Figure 3d,e). These data suggest that CHOP induction is not involved in the mechanism of G1-induced cell death.

A

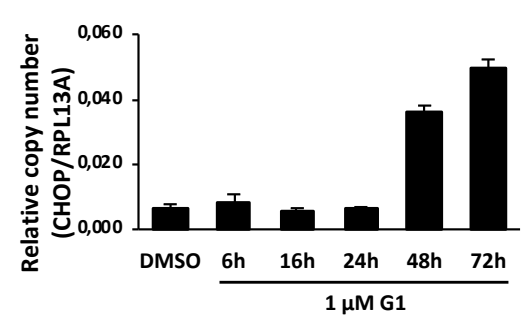

C
B

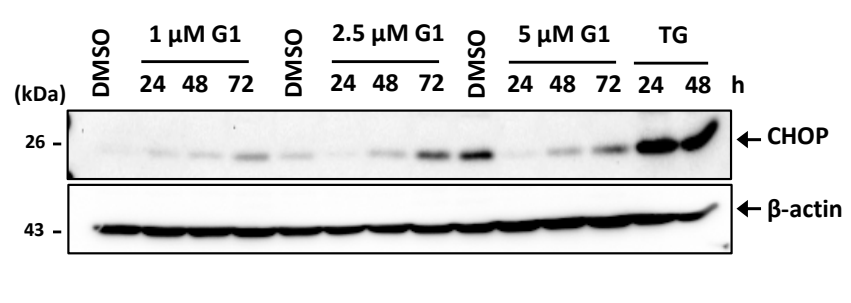

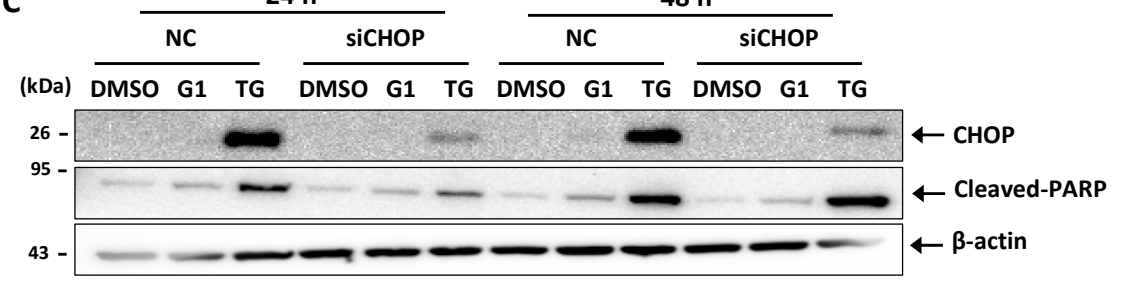

D

口DMSO $\square \mathrm{G} 1$

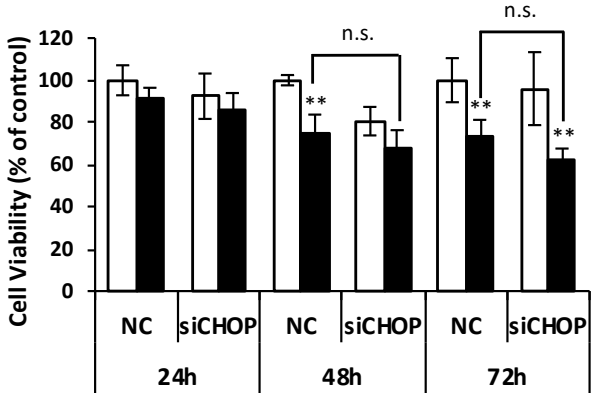

E

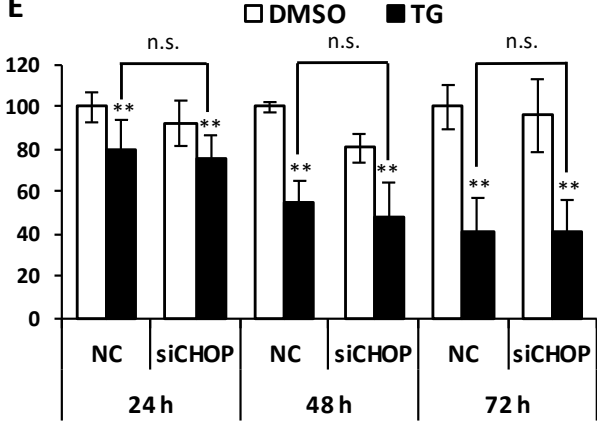

Figure 3. Up-regulation of CHOP expression was not involved in G1-induced cell death in MCF-7 cells. MCF-7 cells were treated with 1, 2.5 and $5 \mu \mathrm{M} \mathrm{G1}$ at different time points. Total mRNA (A) and protein lysates (B) were isolated, and the levels of the expression of CHOP-mRNA were measured by real-time PCR and normalized to RPL13A and Western blotting. MCF-7 cells were transfected with siRNA-CHOP or negative control (NC) for $24 \mathrm{~h}$, and then the cells were challenged with $1 \mu \mathrm{M} \mathrm{G1}$ or $1 \mu \mathrm{M}$ TG for 24,48 and $72 \mathrm{~h}$. (C) Total protein lysates were subjected to Western blotting using appropriate antibodies. (D,E) Cell viability was measured by the LDH activity assay. ${ }^{* *} p<0.01$ when compared with cells treated with vehicle.

3.4. G1 Activated p38 and JNK and a Selective Inhibitor of Phosphorylation of JNK Inhibited G1-Induced Cell Death in MCF-7 Cells

We then examined whether the activation of p38-MAPK and JNK was implicated in G1-induced ER stress and cell death. Both p38 and p46-JNK, as well as p54-JNK were phosphorylated as a response to all tested concentrations of G1 in a 24-h treatment, and the signal became more prominent after $72 \mathrm{~h}$ of treatment compared to the control group. Similar results were obtained with TG-treated cells (Figure 4a), whereas the expression levels of total proteins p38 and JNK were not affected by 
G1 and TG. We then evaluated the effects of the selective kinase inhibitors SB203580 and SP600125, which inhibit the phosphorylation of p38 and JNK, respectively. While SB203580 suppressed the phosphorylation of $\mathrm{p} 38$ induced by G1, the inhibitor could not prevent G1-induced cell death as shown by cell viability analysis and WB results of cleaved-PARP (Figure 4b,c). On the other hand, SP600125 suppressed the phosphorylation of p46-JNK and p54-JNK and significantly inhibited G1-induced cell death (Figure 4d,e). Notably, protein cleavage of PARP was not reduced in cells co-incubated with G1 and SP600125 and rather enhanced in cells treated with SP600125 alone (Figure 4d). This could be the consequence of the self-toxicity of SP600125 on MCF-7 cells, which was shown in cell viability results. Thus, these results indicate that JNK activation plays an important role in the mechanism of G1-induced apoptosis in BC MCF-7 cells.

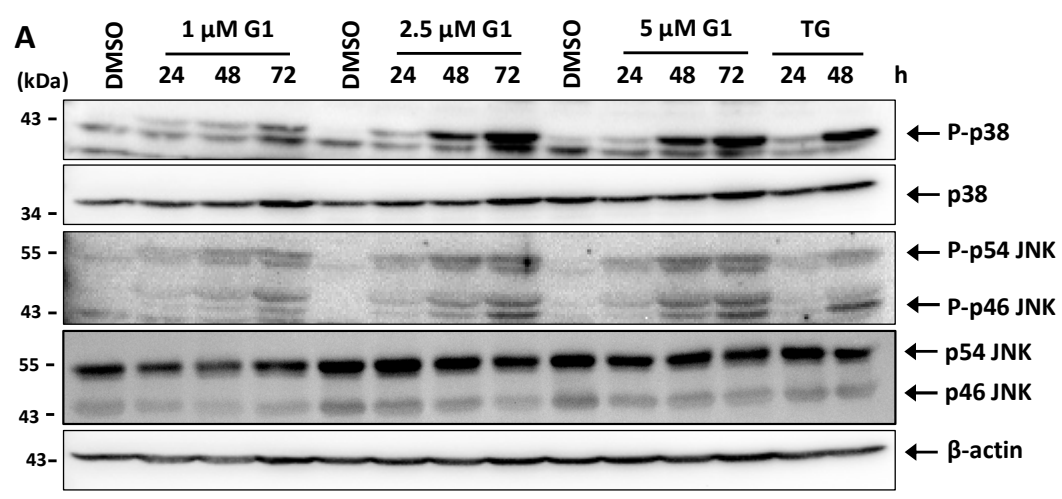

B

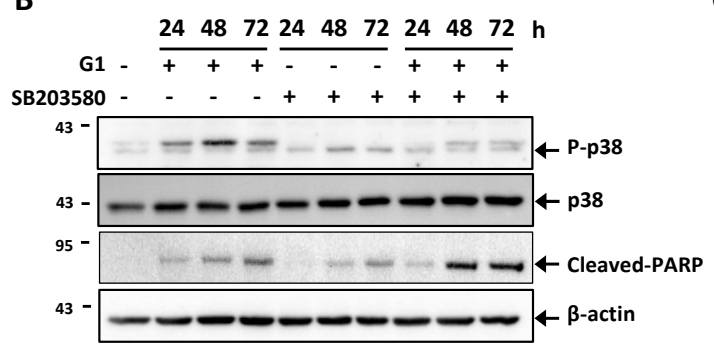

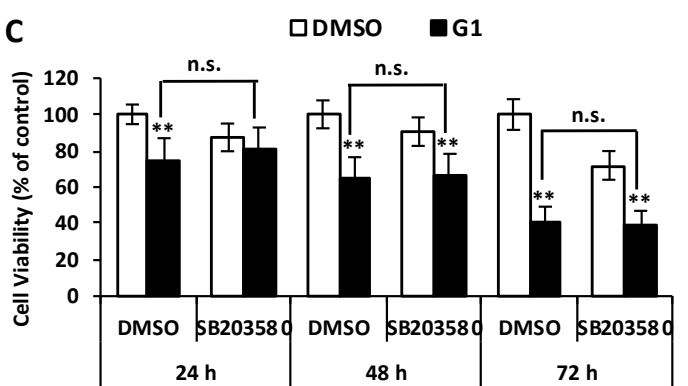

E

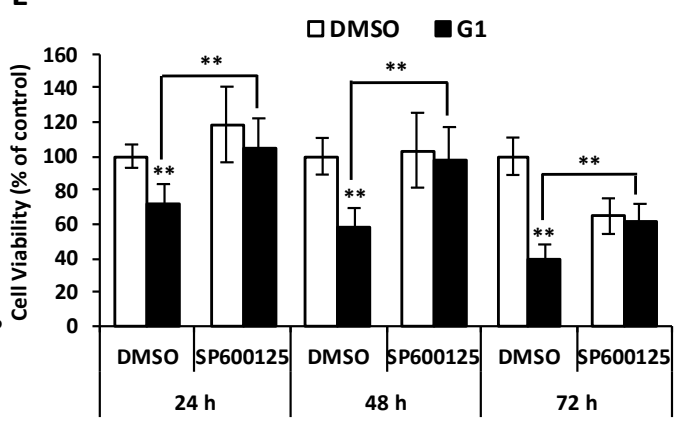

Figure 4. G1 activated p38 and JNK and a selective inhibitor of phosphorylation of JNK inhibited G1-induced cell death in MCF-7 cells. (A) MCF-7 cells were treated with 1, 2.5 and $5 \mu$ M G1 for 24, 48 and $72 \mathrm{~h}$, or with $1 \mu \mathrm{M}$ TG for 24 and $48 \mathrm{~h}$. Total protein lysates were subjected to Western blotting using appropriate antibodies as indicated. Cells were pretreated with $1 \mu \mathrm{M}$ SB203580, a selective inhibitor of p38 MAP kinase or $10 \mu \mathrm{M}$ SP600125, a selective inhibitor of JNK kinase and then exposed to $1 \mu \mathrm{M}$ G1 for 24, 48 and $72 \mathrm{~h}$. (B,D) Total protein lysates were subjected to Western blotting using appropriate antibodies as indicated. (C,E) Cell viability was measured by the LDH activity assay. ${ }^{* *} p<0.01$ when compared with cells treated with vehicle or among G1-treated groups. + is indicated for the presence of a treatment meanwhile - is indicated for the absence of a treatment. 


\subsection{Inhibition of PERK Inhibited the Activation of JNK and Prevented G1-Induced Cell Death in MCF-7 Cells}

We then evaluated whether the activation of PERK could lead to the activation of p38 and JNK in G1-treated cell death. MCF-7 cells were pretreated with $5 \mu$ M GSK2606414, an inhibitor of PERK kinase, for $1 \mathrm{~h}$ and then exposed to $1 \mu \mathrm{M}$ G1 or TG for 24,48 and $72 \mathrm{~h}$. Figure 5 a shows that in all cases, the phosphorylation of PERK was suppressed in the presence of GSK2606414. GSK2606414 also inhibited the phosphorylation of both p46-JNK and p54-JNK, as well as p38, and further reduced the cleavage of PARP in G1- and TG-treated cells. Moreover, co-treatment with $5 \mu \mathrm{M}$ of GSK2606414 significantly prevented G1-induced cell death and slightly mitigated TG-induced cell death (Figure 5b,c), suggesting that p-PERK-mediated p-JNK is directly involved in the mechanism of G1-induced cell death. We also examined the effect of GSK2606414 on the phosphorylation of eIF2 $\alpha$ and a newly synthesized protein. GSK2606414 itself seemed to activate p-eIF2 $\alpha$ and therefore reduced the cap-dependent nascent protein synthesis in vehicle treatment. Following the co-treatment of G1 and GSK2606414, the phosphorylation of eIF $2 \alpha$ was reduced compared to G1 treatment alone (Figure 5a). These results point out that the phosphorylation of PERK by G1 not only regulates translation attenuation but also directly activates JNK to induce apoptosis in BC MCF-7 cells.

\subsection{Inhibition of IRE1 $\alpha$ Inhibited the Phosphorylation of CAMKII and Prevented G1-Induced Cell Death in MCF-7 Cells}

The results shown above raised the question of whether activation of IRE1 $\alpha$ is involved in G1-induced MCF-7 cell death by joining PERK to activate the phosphorylation of p38 and JNK. We used Kira6, an inhibitor of the IRE1 $\alpha$ autophosphorylation, to clarify this hypothesis. A total of $0.05 \mu \mathrm{M}$ of Kira6 showed inhibitory effects on the autophosphorylation of IRE1 $\alpha$ after 48 and 72 h exposure of G1 (Figure 6a). Unlike GSK2606414, Kira6 could not suppress the phosphorylation of JNK but that of p38. Notably, the cleavage of PARP induced by G1 was not changed by Kira6. These results suggest that the phosphorylation of IRE1 $\alpha$ does not activate phosphorylation of JNK. Therefore, we investigated whether CAMKII was activated due to the increase in G1-induced $\mathrm{Ca}^{2+}$ efflux and played a role as a downstream signal of IRE1 $\alpha$-phosphorylation. Both the protein expression levels and phosphorylation of CAMKII were increased in all concentrations of G1 tested after 24, 48 and $72 \mathrm{~h}$ (Figure 6b). Notably, antibody against Thr-286-phosphorylated CAMKII showed two bands at $50 \mathrm{kDa}$ and $60 \mathrm{kDa}$, indicating phosphorylation of CAMKII $\alpha$ and CAMKII $\beta$, respectively. Furthermore, Kira6 could inhibit the phosphorylation of CAMKII (Figure 6a) and significantly inhibited G1-induced cell death (Figure 6c). These results indicate that p-IRE1 $\alpha$-mediated phosphorylation of CAMKII plays a role in G1-induced cell death in MCF-7 cells. 


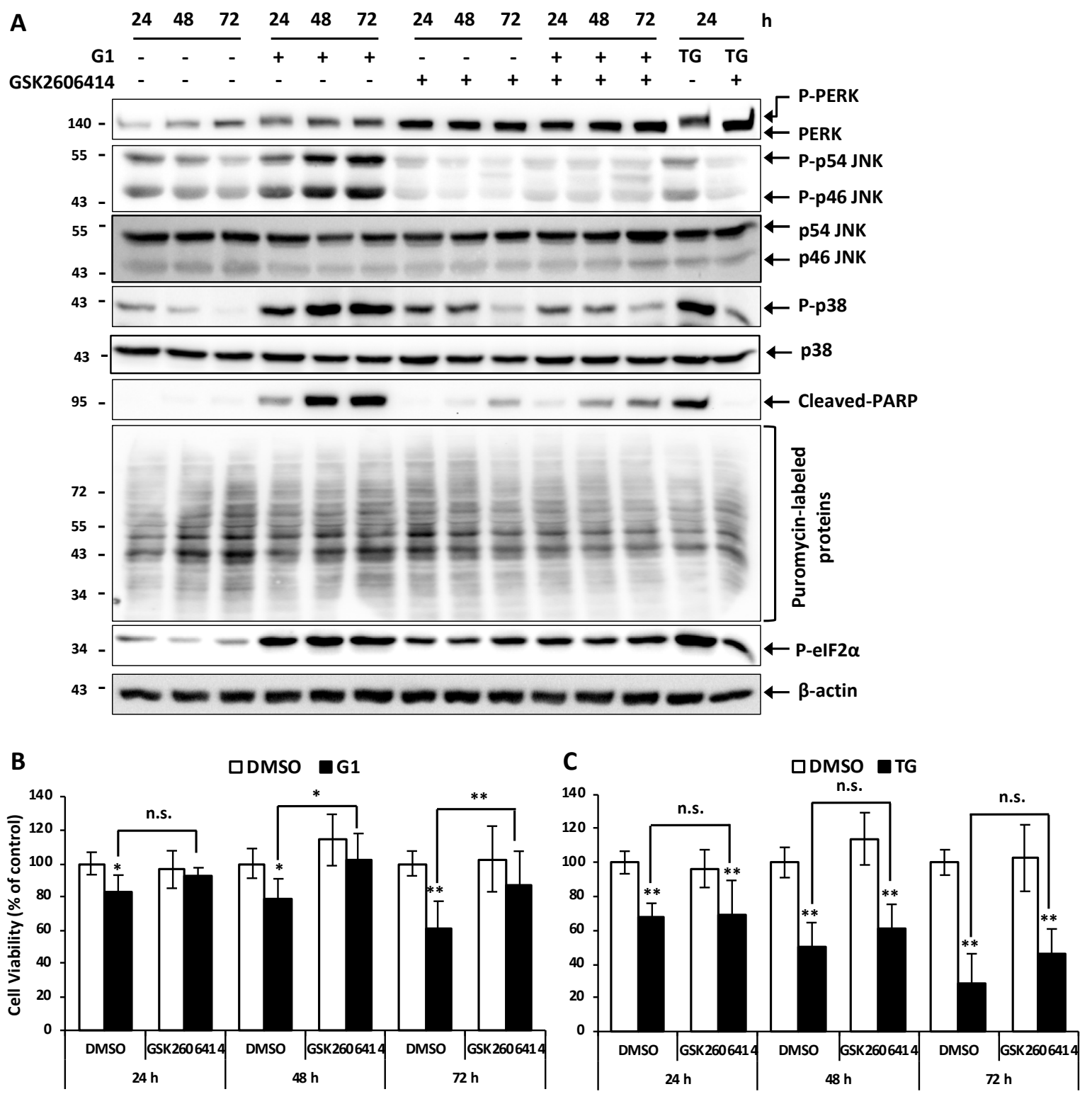

Figure 5. Inhibition of PERK inhibited the activation of JNK and prevented G1-induced cell death in MCF-7 cells. MCF-7 cells were pretreated with $5 \mu$ M GSK2606414, an inhibitor of PERK kinase for $1 \mathrm{~h}$ and then exposed to $1 \mu \mathrm{M}$ G1 or TG for 24,48 and $72 \mathrm{~h}$. (A) Total protein lysates were subjected to Western blotting using appropriate antibodies as indicated. $(\mathbf{B}, \mathbf{C})$ Cell viability was measured by the resazurin assay. ${ }^{*} p<0.05$, and ${ }^{* *} p<0.01$ when compared with cells treated with vehicle or among G1-treated groups. + is indicated for the presence of a treatment meanwhile - is indicated for the absence of a treatment. 


\section{$\begin{array}{llllllllllllll}\text { A } & 24 & 48 & 72 & 24 & 48 & 72 & 24 & 48 & 72 & 24 & 48 & 72 & \text { h }\end{array}$}
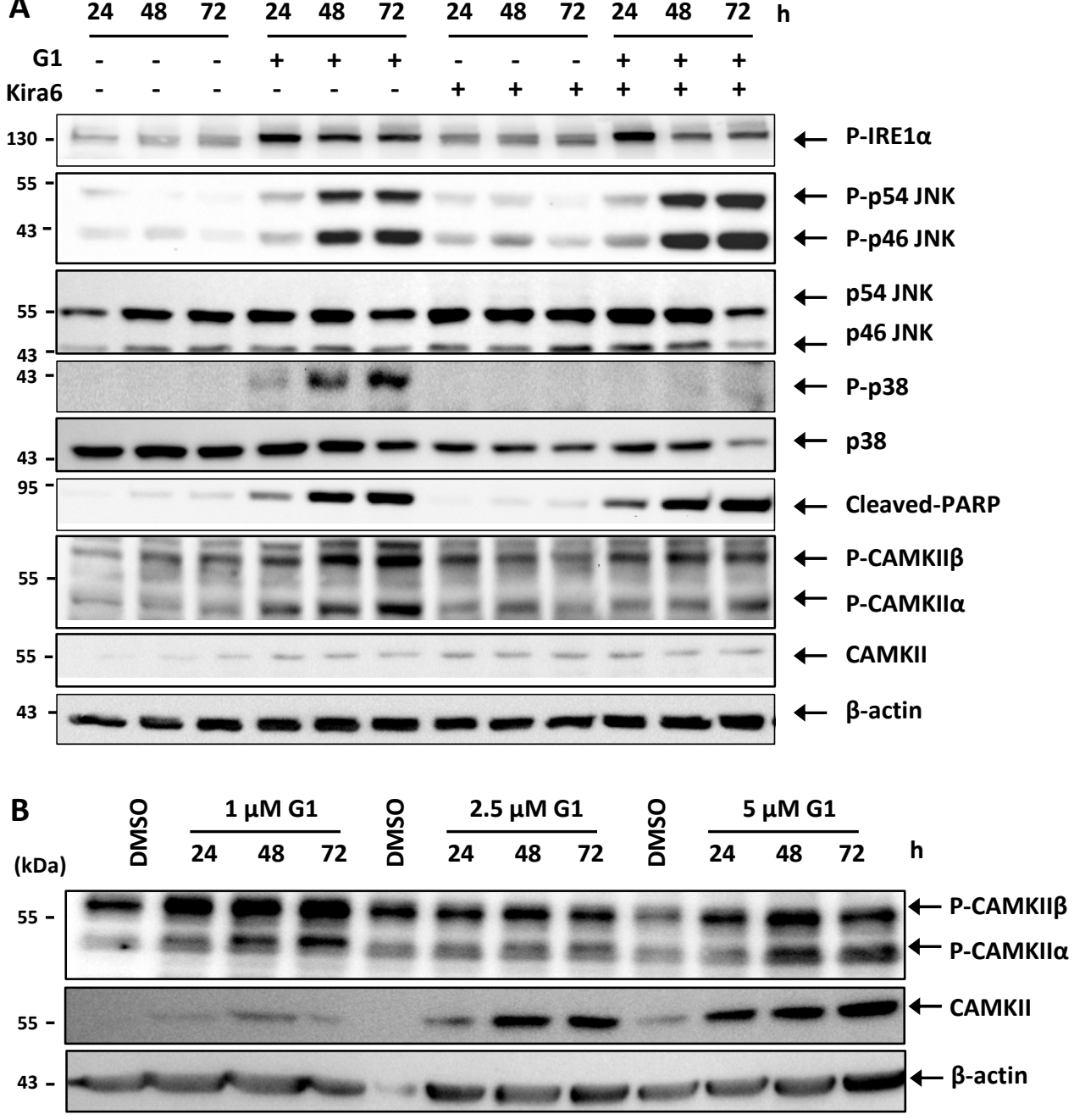

\section{C}

口DMSO GG1

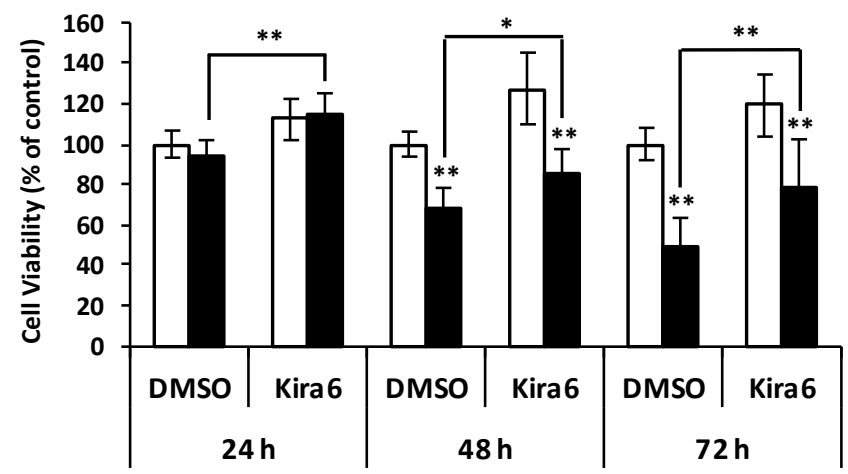

Figure 6. Inhibition of IRE1 $\alpha$ inhibited the phosphorylation of CAMKII and prevented G1-induced cell death in MCF-7 cells. MCF-7 cells were pretreated with $0.05 \mu \mathrm{M}$ Kira6, an inhibitor of IRE1 $\alpha$ for $1 \mathrm{~h}$ and then exposed to $1 \mu \mathrm{M}$ G1 for 24, 48 and $72 \mathrm{~h}$. (A)Total protein lysates were subjected to Western blotting using appropriate antibodies as indicated. (C) Cell viability was measured by the resazurin assay. (B) MCF-7 cells were treated with 1, 2.5 and $5 \mu \mathrm{M} \mathrm{G1}$ for 24, 48 and $72 \mathrm{~h}$. Total protein lysates were subjected to Western blotting using appropriate antibodies as indicated. ${ }^{*} p<0.05$, and ${ }^{* *} p<0.01$ when compared with cells treated with vehicle or among G1-treated groups. + is indicated for the presence of a treatment meanwhile - is indicated for the absence of a treatment. 


\section{Discussion}

GPER is highly expressed in a variety of tissues and often involved in estrogen-dependent diseases. GPER expression is down-regulated in various cancers, and high expression is associated with improved survival of patients with breast and ovarian cancers $[7,8,10,11]$. On the other hand, GPER activation using classical estrogen receptor-interacting ligands, such as $\mathrm{E}_{2}$, tamoxifen and 4-OH tamoxifen, was reported to promote cell proliferation of both epithelial and carcinogenic breast cell lines $[39,40]$. Notably, unlike $E_{2}, G 1$, a quinolone derivative, shows nearly no affinity for estrogen receptor- $\alpha$ and $-\beta$ [17], thus specifically activating GPER. Many research groups have demonstrated that GPER stimulation with high doses of G1, often in the micromolar range, leads to inhibition of growth and proliferation of several BC cell lines [18,21,22]. Although such concentrations are well above the reported IC50 value (3-6 nM), siRNA mediated reduction of GPER expression showed that this inhibitory effect indeed depends on GPER [23]. In models of estrogen receptor (-) BC cells [23] and HCT116 CRC cells in tumor xenograft-bearing mice [12], G1 inhibits tumor growth. In GPER-positive patients, tamoxifen treatment was associated with a significantly shorter disease-free survival compared to those receiving aromatase inhibitors [14]. This indicates that GPER might be involved in tamoxifen resistance of $\mathrm{BC}$.

A previous study has shown that knockdown of GPER in MCF-7 cells but not of estrogen receptor $\alpha$ blocked $\mathrm{E}_{2}$ and G1-induced $\mathrm{Ca}^{2+}$ mobilization [18]. This result indicated that the mobilization of intracellular $\mathrm{Ca}^{2+}$ stores is dependent on GPER. Moreover, the increase in the intracellular concentration of $\mathrm{Ca}^{2+}$ upon stimulation of GPER by G1 has also been reported in estrogen receptor (-) BC cells and cancer-associated fibroblasts [40]. Little is known about a link between the mobilization of intracellular $\mathrm{Ca}^{2+}$ stores and cell death when GPER is stimulated by G1. As the ER lumen is the major source of intracellular $\mathrm{Ca}^{2+}$, loss of $\mathrm{Ca}^{2+}$ can promote a variety of signaling mechanisms that might lead to cell death. The present study shows that G1-induced $\mathrm{Ca}^{2+}$ efflux activates the UPR in MCF-7 cells accompanied by the activation of IRE1 $\alpha$, PERK and ATF6. It is likely that a pro-survival UPR is activated by upregulation of GRP78 to assist an accumulation of unfolded proteins in the ER lumen and phosphorylation of eIF $2 \alpha$ to reduce translation of nascent proteins. We further show that G1-induced ER $\mathrm{Ca}^{2+}$ mobilization prominently activates the pro-death UPR signaling pathways. $\mathrm{CHOP}$ is upregulated but not involved in the G1-induced cell death machinery. Unlike the signaling observed in previous studies [29], we found that phosphorylation of PERK but not of IRE1 $\alpha$ stimulates the activation of downstream kinase JNK to directly induce cell death in G1-treated MCF-7 cells. On the other hand, G1-induced p-IRE1 $\alpha$ does not activate the XBP1s but rather enhances the activation of CAMKII and is therefore implicated in G1-induced cell death (Figure 7).

To the best of our knowledge, we are the first to reveal a connection where stimulation of GPER by its agonist G1 induced ER $\mathrm{Ca}^{2+}$ efflux, leading to ER stress-induced apoptosis in the estrogen receptor-positive MCF-7 cells. Clearly, further studies are needed to demonstrate that this mechanism is also important for other cell lines that show G1-induced cell death and Ca-fluxes. According to Ariazi et al., inhibitors of ER Ca ${ }^{2+}$ channels in the ER membrane, including $\mathrm{IP}_{3} \mathrm{Rs}$ and RyRs, could suppress G1-induced $\mathrm{Ca}^{2+}$ efflux in MCF-7 and SKBRr3 cells, respectively [18]. These results are in line with our findings, indicating that the release of $\mathrm{Ca}^{2+}$ from the ER via $\mathrm{IP}_{3} \mathrm{Rs}$ and/or RyRs triggers UPR-dependent apoptosis. In this study, we used TG as a positive control, as it is known to block the pumping of cytosolic $\mathrm{Ca}^{2+}$ to the ER, leading to ER stress. Similar to G1, TG showed an activation of UPR signaling, and the inhibitor of p-PERK slightly inhibited TG-induced apoptosis. Our previous study of Neuronatin (NNAT), a proteolipid involved in the regulation of $\mathrm{Ca}^{2+}$-channels, showed that high expression of NNAT was significantly associated with poor prognosis for overall survival in BC patients [41]. Drugs targeting $\mathrm{Ca}^{2+}$ channels/transporters/pumps for cancer treatment have been widely studied in pre-clinical research and even in clinical trials, some compounds of which have shown promising anti-cancer abilities [42]. Therefore, GPER might serve as a potential therapeutic target causing intracellular $\mathrm{Ca}^{2+}$ depletion. 


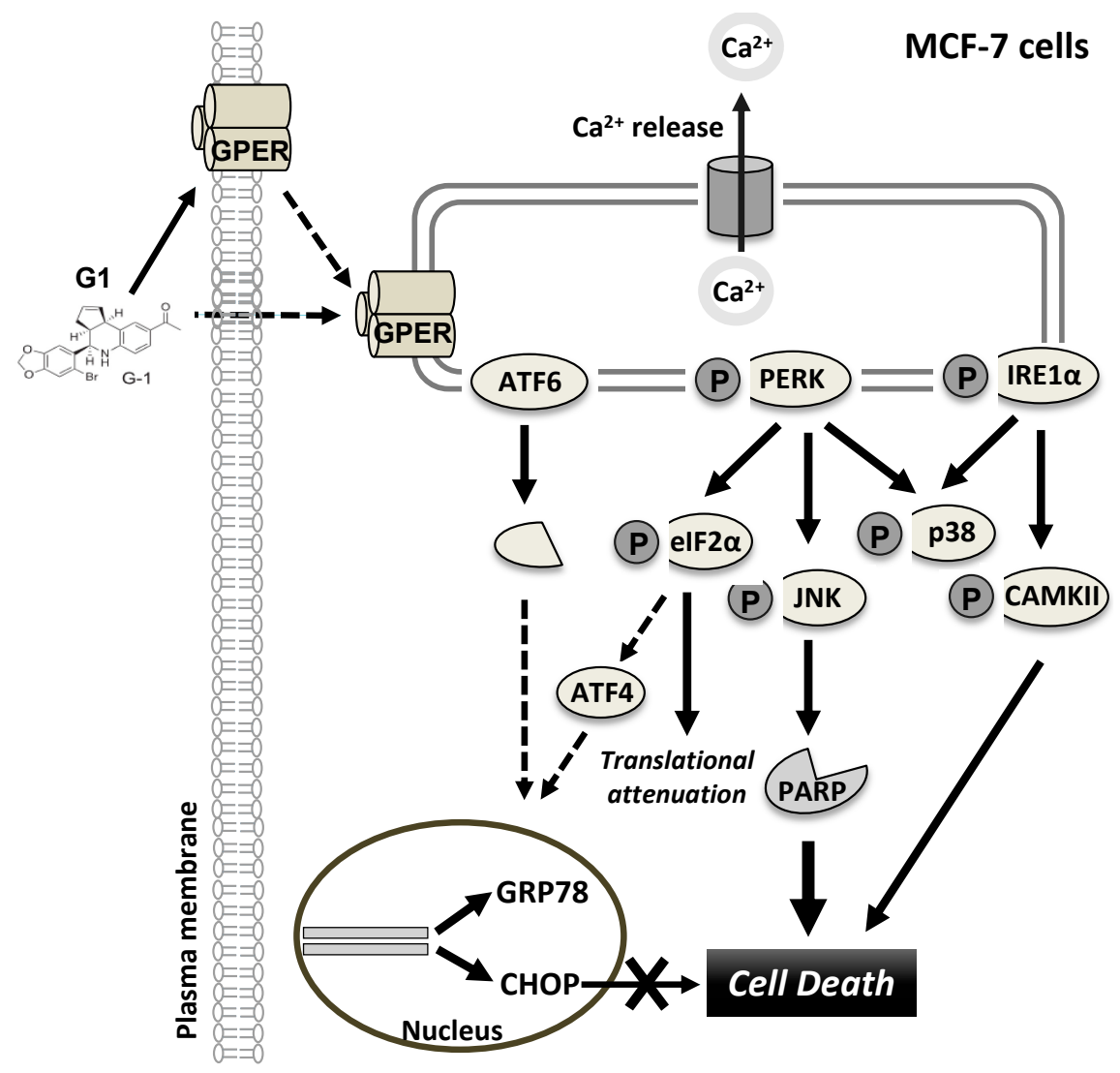

Figure 7. Model of the proposed mechanism of G1-induced cell death. G1 leads to a decrease of ER $\mathrm{Ca}^{2+}$ stores in MCF-7 cells, and this event activates the UPR in MCF-7 cells, including the activation of IRE1 $\alpha$, PERK and ATF6. The pro-survival UPR is activated exhibiting upregulation of GRP78 to assist the proper folding capacity of the ER and eIF2 $\alpha$-phosphorylation to reduce translation of nascent proteins. However, pro-death UPR signaling plays a major role in G1-induced ER stress, which, in turn, regulates cell death. CHOP is upregulated but not involved in the G1-induced cell death machinery. In contrast, phosphorylation of both PERK and IRE1 $\alpha$ is implicated in G1-induced cell death. Phosphorylation of PERK stimulates the activation of downstream kinase JNK to directly induce apoptosis, while phosphorylation of IRE1 $\alpha$ induces phosphorylation of CAMKIII.

Many studies have shown that G1 possesses a strong inhibitory effect on cell growth in GPER-expressing cancer cells [21-23,43,44]. Most of these studies report that activation of GPER by its specific agonist $\mathrm{G} 1$ inhibits proliferation by inducing cell cycle arrest at $\mathrm{G} 2 / \mathrm{M}$, enhances phosphorylation of histone 3, induces nuclear translocation of ERK1/2 and induces apoptosis by activating caspase 3 and 9. We confirmed that G1 induces cell cycle arrest at G2/M and late apoptosis in MCF-7 cells, which is in line with previous reports. However, we further showed that G1 induces PARP-dependent apoptosis independent of caspase 3 and 9. PARP is one of several cellular substrates of caspases. Cleavage of PARP by caspases is considered to be a hallmark of apoptosis [45]. In addition to caspase 3 and 9, cleavage of PARP could also occur by other caspases like caspase 7 or proteases including cathepsins [46]. Addition of zVAD-fmk blocks PARP processing, but it was reported that zVAD-fmk blocks not only the protease activity of caspases but also that of cathepsins [46]. Further investigations are required to identify the protease responsible for cleavage of PARP in the mechanism of G1-induced non-canonical apoptosis in MCF-7 cells. It should be taken into account that the concentration of G1 used in our and other studies is above the reported IC50 value (3-6 nM). However, G1 showed a specific effect on GPER stimulation indicating in both knockdown of GPER in cancer cell lines which improved cell proliferation and in vivo experiments on tumor xenograft mice models of estrogen receptor (-) BC cells [23], HCT116 CRC [12] and ASG or SNU-216 gastric cancer [44] where tumor 
size is reduced by G1. Nevertheless, it cannot be completely excluded that other binding proteins contribute to the cell death mechanism at this saturating concentration.

Our results also demonstrated a direct involvement of PERK and IRE1 $\alpha$ in G1-induced MCF-7 cell death. GSK2606414 and Kira6, inhibitors of phosphorylation of PERK and IRE1 $\alpha$, respectively, significantly suppressed cell death upon GPER stimulation by G1, indicating ER stress-dependent cell death. However, downstream, activation of CHOP was not involved, but SP600125, a selective inhibitor of JNK-phosphorylation, suppressed G1-induced cell death. It is also known that IRE1 $\alpha$ stimulates the activation of the stress kinases JNK and p38 [25]. Under severe ER stress conditions, JNK then eliminates the anti-apoptotic effects of BCL-2 by phosphorylation or leads to the activation of Bax or Bak by phosphorylating Bim, eventually activating cell death via mitochondria [47]. Although we observed an up-regulation of Bax (data not shown), a mitochondrial function is not implicated in G1-induced apoptosis. Notably, in most reports involving $\mathrm{Ca}^{2+}$-mediated cell death mechanism, mitochondria play a major role by coupling ER-stress to apoptosis. In general, anti-apoptotic factors like BCL-2 reduce the intracellular ER Ca ${ }^{2+}$ concentration, which, however, is increased by Bax and Bak, eventually leading to the release of cytochrome $\mathrm{c}$ to trigger apoptosis [48]. Liu et al. reported that stimulation of GPER by G1 induced apoptosis in CRC is dependent on mitochondria but not on ER stress [12]. Wei et al. also showed that G1 inhibited the growth of estrogen receptor (-) BC and induced mitochondria-related apoptosis [23]. In contrast to these studies, we revealed a different cell death mechanism induced by G1 in MCF-7 cells that is characterized by a new role of PERK in unresolved $\mathrm{Ca}^{2+}$ efflux-induced ER stress, where it directly activates the pro-apoptotic JNK protein and independent of mitochondrial function. On the other hand, a recent study by Lee et al. strongly supported our result which showed the dependence of PERK induction in G1-induced cell death in ASG gastic cancer cells and silencing of PERK reduced ER stress signals in the downstream incuding ATF4, CHOP; prevented cell death and increased GPER expression [44]. Moreover, our results might suggest a novel cell death mechanism in eukaryotic cancer cells where JNK is activated directly via p-PERK instead of p-IRE1 $\alpha$. Similar results were observed in a chronic ER stress Drosophila model, where PERK/ATF4 activated the JNK pathway through Rac1 and Slpr activation in apoptotic cells, leading to the expression of Dilp8 and thus to a developmental delay [49].

Recent evidence suggests that several signaling pathways are involved in the connection between CAMKII and unresolved ER stress-induced apoptosis. For example, CHOP promotes ER $\mathrm{Ca}^{2+}$ release and the subsequent activation of CAMKII downstream the ASK1-JNK signaling cascade, leading to cell death [50]. Otherwise, CAMKII can be the last target in the signaling cascade of CHOP-IRO1 $\alpha$-IP3R1-CAMKII in tunicamycin-induced ER stress [51]. To the best of our knowledge, there is no report on a signaling pathway where CAMKII is directly induced by IRE1 $\alpha$ in ER stress-induced cell death. Our results reveal a connection between IRE1 $\alpha$ and CAMKII, in which Kira6 inhibits the phosphorylation of CAMKII and G1-induced cell death. It would be interesting to further investigate the role of IRE1 $\alpha$-CAMKII in G1-induced cell death.

Recent research indicates that estrogens and related compounds can also drive cells into apoptosis. HeLa cells undergo apoptosis upon incubation with estrogens E1 and E2 at $10 \mu \mathrm{M}$ concentration whereas E3, genistein and zearalanone were nearly ineffective [52]. In this case phosphodiesterase 3A was found to be the target molecule and apoptosis was dependent on caspase 9 and the mitochondrial pathway. Interestingly this was mediated by Schlafen 12 which interferes with the protein biosynthesis at the ER. Zearalenone, a Fusarium-derived estrogenic mycotoxin causes ER-stress in bovine mammary epithelial cells at $30 \mu \mathrm{M}$ resulting also in apoptosis via the mitochondrial pathway [53]. For both cases, the proposed apoptotic mechanism is different to the one we propose here for G-1 induced cell death in MCF-7 breast cancer cells. Nevertheless, this clearly shows that the relation between estrogenic compounds and apoptotic cell death needs to be further investigated.

Additional investigations are required to fully address the features and specificities of the stimulation of GPER by its specific agonist G1 in cancer. Our study revealed a connection between $\mathrm{ER} \mathrm{Ca}^{2+}$ mobilization and the pro-death UPR signaling, triggering MCF-7 cell death when GPER is 
stimulated by its specific agonist G1. However, our study is limited to one single cell line of estrogen receptor positive MCF-7 BC cells. Further studies using other cell lines would be required to support previous research defining GPER as a target for breast cancer therapy.

\section{Conclusions}

G1-induced $\mathrm{Ca}^{2+}$ efflux activates the UPR in MCF-7 cells accompanied by the activation of IRE1 $\alpha$, PERK and ATF6. Although the pro-survival UPR is activated, the pro-death UPR is dominantly stimulated and responsible for G1-induced cell death. Mechanistically, phosphorylation of PERK stimulates the activation of downstream kinase JNK to directly induce apoptosis. On the other hand, G1-induced p-IRE1 $\alpha$ does not activate the XBP1s but rather enhances the activation of CAMKII and is therefore also implicated in G1-induced cell death. Our results support previous research promoting GPER as a target for breast cancer therapy.

Supplementary Materials: The following are available online at http://www.mdpi.com/2218-273X/9/9/503/s1, Figure S1. Caspase 3 was absent in MCF-7 cells. Total protein lysates from SK-BR-3, MDA-MB-231 and MCF-7 were subjected to Western blotting using appropriate antibodies as indicated. Figure S2. G1-induced cell death was not involved in the functional loss of mitochondrial potential. (A) MCF-7 cells were stimulated with $1 \mu$ M G1 or TG at different time points. Fluorescent signals of mitochondrial potential were measured by flow cytometry in TMRE-stained cells. CCCP was used as a positive control, which causes an uncoupling of mitochondria by inhibiting oxidative phosphorylation. (B) MCF-7 cells were treated with $1 \mu \mathrm{M}$ G1 for 24,48 and $72 \mathrm{~h} ; 1 \mu \mathrm{M}$ TG for 24 and $48 \mathrm{~h}$ or with $1 \mu \mathrm{M}$ Staurosporine (STS) for $3 \mathrm{~h}$. Subcellular fractionation was performed to collect cytosolic-enriched digitonin extract and membrane organellar protein-enriched NP-40 extract. Equal aliquots from each fraction were subjected to Western blotting using appropriate antibodies as indicated.

Author Contributions: D.-K.H.V. designed and performed the experiments, performed statistical analysis, interpreted the data and wrote the manuscript; R.H and N.N. carried out the following experiments: cell cycle and apoptosis analysis, Indo-1 AM staining using flow cytometry, mitochondrial potential measurement; S.W. and J.H. reviewed and edited the manuscript; N.N. discussed and interpreted experiments, reviewed and edited the manuscript.

Funding: This research received no external funding.

Acknowledgments: We thank Kerstin Werner for her excellent technical supports.

Conflicts of Interest: The authors declare no conflict of interest.

\section{References}

1. Anchisi, L.; Dessi, S.; Pani, A.; Mandas, A. Cholesterol homeostasis: A key to prevent or slow down neurodegeneration. Front. Physiol. 2012, 3, 486. [CrossRef]

2. Olde, B.; Leeb-Lundberg, L.M. GPR30/GPER1: Searching for a role in estrogen physiology. Trends Endocrin. Met. 2009, 20, 409-416. [CrossRef] [PubMed]

3. Filardo, E.J.; Quinn, J.A.; Bland, K.I.; Frackelton, A.R., Jr. Estrogen-induced activation of Erk-1 and Erk-2 requires the G protein-coupled receptor homolog, GPR30, and occurs via trans-activation of the epidermal growth factor receptor through release of HB-EGF. Mol. Endocrinol. 2000, 14, 1649-1660. [CrossRef]

4. Revankar, C.M.; Cimino, D.F.; Sklar, L.A.; Arterburn, J.B.; Prossnitz, E.R. A transmembrane intracellular estrogen receptor mediates rapid cell signaling. Science 2005, 307, 1625-1630. [CrossRef] [PubMed]

5. Prossnitz, E.R.; Arterburn, J.B. International Union of Basic and Clinical Pharmacology. XCVII. G Protein-Coupled Estrogen Receptor and Its Pharmacologic Modulators. Pharmacol. Rev. 2015, 67, 505-540. [CrossRef] [PubMed]

6. Lappano, R.; Pisano, A.; Maggiolini, M. GPER Function in Breast Cancer: An Overview. Front. Endocrinol. 2014, 5, 66. [CrossRef]

7. Ignatov, T.; Weißenborn, C.; Poehlmann, A.; Lemke, A.; Semczuk, A.; Roessner, A.; Costa, S.D.; Kalinski, T.; Ignatov, A. GPER-1 expression decreases during breast cancer tumorigenesis. Cancer Investig. 2013, 31, 309-315. [CrossRef] [PubMed]

8. Liu, Q.; Li, J.G.; Zheng, X.Y.; Jin, F.; Dong, H.T. Expression of CD133, PAX2, ESA, and GPR30 in invasive ductal breast carcinomas. Chin. Med. J. 2009, 122, 2763-2769. [PubMed] 
9. Ignatov, A.; Ignatov, T.; Weißenborn, C.; Eggemann, H.; Bischoff, J.; Semczuk, A.; Roessner, A.; Costa, S.D.; Kalinski, T. G-protein-coupled estrogen receptor GPR30 and tamoxifen resistance in breast cancer. Breast Cancer Res. Treat. 2011, 128, 457-466. [CrossRef] [PubMed]

10. Arias-Pulido, H.; Royce, M.; Gong, Y.; Joste, N.; Lomo, L.; Lee, S.J.; Chaher, N.; Verschraegen, C.; Lara, J.; Prossnitz, E.R.; et al. GPR30 and estrogen receptor expression: New insights into hormone dependence of inflammatory breast cancer. Breast Cancer Res. Treat. 2010, 123, 51-58. [CrossRef]

11. Ignatov, T.; Modl, S.; Thulig, M.; Weißenborn, C.; Treeck, O.; Ortmann, O.; Zenclussen, A.C.; Costa, S.D.; Kalinski, T.; Ignatov, A. GPER-1 acts as a tumor suppressor in ovarian cancer. J. Ovarian Res. 2013, 6, 51. [CrossRef] [PubMed]

12. Liu, Q.; Chen, Z.; Jiang, G.; Zhou, Y.; Yang, X.; Huang, H.; Liu, H.; Du, J.; Wang, H. Epigenetic down regulation of $\mathrm{G}$ protein-coupled estrogen receptor (GPER) functions as a tumor suppressor in colorectal cancer. Mol. Cancer 2017, 16, 87. [CrossRef] [PubMed]

13. Filardo, E.J.; Graeber, C.T.; Quinn, J.A.; Resnick, M.B.; Giri, D.; DeLellis, R.A.; Steinhoff, M.M.; Sabo, E. Distribution of GPR30, a seven membrane-spanning estrogen receptor, in primary breast cancer and its association with clinicopathologic determinants of tumor progression. Clin. Cancer Res. 2006, 12, 6359-6366. [CrossRef] [PubMed]

14. Ignatov, T.; Claus, M.; Nass, N.; Haybaeck, J.; Seifert, B.; Kalinski, T.; Ortmann, O.; Ignatov, A. G-protein-coupled estrogen receptor GPER-1 expression in hormone receptor-positive breast cancer is associated with poor benefit of tamoxifen. Breast Cancer Res. Treat. 2019, 174, 121-127. [CrossRef] [PubMed]

15. Ignatov, A.; Ignatov, T.; Roessner, A.; Costa, S.D.; Kalinski, T. Role of GPR30 in the mechanisms of tamoxifen resistance in breast cancer MCF-7 cells. Breast Cancer Res. Treat. 2010, 123, 87-96. [CrossRef] [PubMed]

16. Mo, Z.; Liu, M.; Yang, F.; Luo, H.; Li, Z.; Tu, G.; Yang, G. GPR30 as an initiator of tamoxifen resistance in hormone-dependent breast cancer. Breast Cancer Res. 2013, 15, R114. [CrossRef] [PubMed]

17. Bologa, C.G.; Revankar, C.M.; Young, S.M.; Edwards, B.S.; Arterburn, J.B.; Kiselyov, A.S.; Parker, M.A.; Tkachenko, S.E.; Savchuck, N.P.; Sklar, L.A.; et al. Virtual and biomolecular screening converge on a selective agonist for GPR30. Nat. Chem. Biol. 2006, 2, 207-212. [CrossRef]

18. Ariazi, E.A.; Brailoiu, E.; Yerrum, S.; Shupp, H.A.; Slifker, M.J.; Cunliffe, H.E.; Black, M.A.; Donato, A.L.; Arterburn, J.B.; Oprea, T.I.; et al. The G protein-coupled receptor GPR30 inhibits proliferation of estrogen receptor-positive breast cancer cells. Cancer Res. 2010, 70, 1184-1194. [CrossRef] [PubMed]

19. Chan, Q.K.; Lam, H.M.; Ng, C.F.; Lee, A.Y.; Chan, E.S.; Ng, H.K.; Ho, S.M.; Lau, K.M. Activation of GPR30 inhibits the growth of prostate cancer cells through sustained activation of Erk1/2, c-jun/c-fos-dependent upregulation of p21, and induction of G(2) cell-cycle arrest. Cell Death Differ. 2010, 17, 1511-1523. [CrossRef] [PubMed]

20. Chimento, A.; Casaburi, I.; Rosano, C.; Avena, P.; De Luca, A.; Campana, C.; Martire, E.; Santolla, M.F.; Maggiolini, M.; Pezzi, V.; et al. Oleuropein and hydroxytyrosol activate GPER/ GPR30-dependent pathways leading to apoptosis of ER-negative SKBR3 breast cancer cells. Mol. Nutr. Food Res. 2014, 58, 478-489. [CrossRef] [PubMed]

21. Weissenborn, C.; Ignatov, T.; Ochel, H.J.; Costa, S.D.; Zenclussen, A.C.; Ignatova, Z.; Ignatov, A. GPER functions as a tumor suppressor in triple-negative breast cancer cells. J. Cancer Res. Clin. 2014, 140, 713-723. [CrossRef] [PubMed]

22. Weissenborn, C.; Ignatov, T.; Poehlmann, A.; Wege, A.K.; Costa, S.D.; Zenclussen, A.C.; Ignatov, A. GPER functions as a tumor suppressor in MCF-7 and SK-BR-3 breast cancer cells. J. Cancer Res. Clin. 2014, 140, 663-671. [CrossRef] [PubMed]

23. Wei, W.; Chen, Z.J.; Zhang, K.S.; Yang, X.L.; Wu, Y.M.; Chen, X.H.; Huang, H.B.; Liu, H.L.; Cai, S.H.; $\mathrm{Du}$, J.; et al. The activation of $\mathrm{G}$ protein-coupled receptor 30 (GPR30) inhibits proliferation of estrogen receptor-negative breast cancer cells in vitro and in vivo. Cell Ceath Dis. 2014, 5, e1428. [CrossRef] [PubMed]

24. Ji, Y.; Han, Z.; Shao, L.; Zhao, Y. Ultrasound-targeted microbubble destruction of calcium channel subunit alpha 1D siRNA inhibits breast cancer via G protein-coupled receptor 30. Oncol. Rep. 2016, 36, 1886-1892. [CrossRef] [PubMed]

25. Sano, R.; Reed, J.C. ER stress-induced cell death mechanisms. Biochim. Biophys. Acta 2013, 1833, 3460-3470. [CrossRef] [PubMed]

26. Hetz, C. The unfolded protein response: Controlling cell fate decisions under ER stress and beyond. Nat. Rev. Mol. Cell Bio. 2013, 13, 89-102. [CrossRef] [PubMed] 
27. Kroemer, G.; Galluzzi, L.; Brenner, C. Mitochondrial membrane permeabilization in cell death. Physiol. Rev. 2007, 87, 99-163. [CrossRef] [PubMed]

28. Urano, Y.; Vo, H.D.K.; Hirofumi, A.; Noguchi, N. 24(S)-Hydroxycholesterol induces ER dysfunction-mediated unconventional cell death. Cell Ceath Discov. 2019, 5, 113. [CrossRef]

29. Ron, D.; Hubbard, S.R. How IRE1 reacts to ER stress. Cell 2008, 132, 24-26. [CrossRef]

30. Yamaguchi, H.; Wang, H.G. CHOP is involved in endoplasmic reticulum stress-induced apoptosis by enhancing DR5 expression in human carcinoma cells. J. Biol. Chem. 2004, 279, 45495-45502. [CrossRef]

31. Li, Y.; Guo, Y.; Tang, J.; Jiang, J.; Chen, Z. New insights into the roles of CHOP-induced apoptosis in ER stress. Acta Biochim. Biophys. Sin. 2014, 46, 629-640. [CrossRef] [PubMed]

32. Denmeade, S.R.; Jakobsen, C.M.; Janssen, S.; Khan, S.R.; Garrett, E.S.; Lilja, H.; Christensen, S.B.; Isaacs, J.T. Prostate-specific antigen-activated thapsigargin prodrug as targeted therapy for prostate cancer. J. Natl. Cancer Inst. 2003, 95, 990-1000. [CrossRef] [PubMed]

33. Anand, P.; Sundaram, C.; Jhurani, S.; Kunnumakkara, A.B.; Aggarwal, B.B. Curcumin and cancer: An "old-age" disease with an "age-old" solution. Cancer Lett. 2008, 267, 133-164. [CrossRef] [PubMed]

34. Vo, D.K.; Urano, Y.; Takabe, W.; Saito, Y.; Noguchi, N. 24(S)-Hydroxycholesterol induces RIPK1-dependent but MLKL-independent cell death in the absence of caspase-8. Steroids 2015, 99, 230-237. [CrossRef] [PubMed]

35. Pereira, M.; Millot, J.M.; Sebille, S.; Manfait, M. Inhibitory effects of extracellular $\mathrm{Mg}^{2+}$ on intracellular Ca ${ }^{2+}$ dynamic changes and thapsigargin-induced apoptosis in human cancer MCF7 cells. Mol. Cell. Biochem. 2002, 229, 163-171. [CrossRef]

36. Van Noorden, C.J. The history of Z-VAD-FMK, a tool for understanding the significance of caspase inhibition. Acta Histochem. 2001, 103, 241-251. [CrossRef] [PubMed]

37. Schmidt, E.K.; Clavarino, G.; Ceppi, M.; Pierre, P. SUnSET, a nonradioactive method to monitor protein synthesis. Nat. Methods 2009, 6, 275-277. [CrossRef]

38. Lim, M.L.; Minamikawa, T.; Nagley, P. The protonophore CCCP induces mitochondrial permeability transition without cytochrome c release in human osteosarcoma cells. FEBS Lett. 2001, 503, 69-74. [CrossRef]

39. Scaling, A.L.; Prossnitz, E.R.; Hathaway, H.J. GPER mediates estrogen-induced signaling and proliferation in human breast epithelial cells and normal and malignant breast. Horm. Cancer 2014, 5, 146-160. [CrossRef]

40. Luo, H.; Yang, G.; Yu, T.; Luo, S.; Wu, C.; Sun, Y.; Liu, M.; Tu, G. GPER-mediated proliferation and estradiol production in breast cancer-associated fibroblasts. Endocr. Relat. Cancer 2014, 21, 355-369. [CrossRef]

41. Nass, N.; Walter, S.; Jechorek, D.; Weissenborn, C.; Ignatov, A.; Haybaeck, J.; Sel, S.; Kalinski, T. High neuronatin (NNAT) expression is associated with poor outcome in breast cancer. Virchows Arch. 2017, 471, 23-30. [CrossRef] [PubMed]

42. Cui, C.; Merritt, R.; Fu, L.; Pan, Z. Targeting calcium signaling in cancer therapy. Acta Pharm. Sin. B 2017, 7, 3-17. [CrossRef] [PubMed]

43. Holm, A.; Baldetorp, B.; Olde, B.; Leeb-Lundberg, L.M.; Nilsson, B.O. The GPER1 agonist G-1 attenuates endothelial cell proliferation by inhibiting DNA synthesis and accumulating cells in the S and G2 phases of the cell cycle. J. Vasc. Res. 2011, 48, 327-335. [CrossRef] [PubMed]

44. Lee, S.J.; Kim, T.W.; Park, G.L.; Hwang, Y.S.; Cho, H.J.; Kim, J.T.; Lee, H.G. G protein-coupled estrogen receptor-1 agonist induces chemotherapeutic via ER stress signaling in gastric cancer. BMB Rep. 2019.

45. Alvarez-Gonzalez, R.; Spring, H.; Müller, M.; Bürkle, A. Selective loss of Poly(ADP-ribose) and the 85-kDa Fragment of Poly(ADP-ribose) Polymerase in Nucleoli during Alkylation-induced apoptosis of Hela cells. J. Biol. Chem. 1999, 274, 32122-32126. [CrossRef] [PubMed]

46. Chaitanya, G.V.; Steven, A.J.; Babu, P.P. PARP-1 cleavage fragemnts: Signatures of cell-death proteases in neurodegeneration. Cell. Commun. Signal. 2010, 8, 31. [CrossRef]

47. Szegezdi, E.; Logue, S.E.; Gorman, A.M.; Samali, A. Mediatora of endoplasmic reticulum stress-induced apoptosis. EMBO Rep. 2006, 7, 800-995. [CrossRef]

48. Orrenius, S.; Zhivotovsky, B.; Nicotera, P. Regulation of cell death: The calcium-apoptosis link. Nat. Rev. Mol. Cell Biol. 2003, 4, 552-565. [CrossRef]

49. Demay, Y.; Perochon, J.; Szuplewski, S.; Mignotte, B.; Gaumer, S. The PERK pathway independently triggers apoptosis amd a Rac1/Slpr/JNKJ/Dilp8 signaling favoring tissue homeostasis in a chronic ER stress Drosophila model. Cell Death Dis. 2014, 5, e1454. [CrossRef] 
50. Timmins, J.M.; Ozcan, L.; Seimon, T.A.; Li, G.; Malagelada, C.; Backs, J.; Backs, T.; Bassel-Duby, R.; Olson, E.N.; Anderson, M.E.; et al. Calcium/calmodulin-dependent protein kinase II links ER stress with Fas and mitochondrial apoptosis pathways. J. Clin. Investig. 2009, 119, 2925-2941. [CrossRef]

51. Li, G.; Mongillo, M.; Chin, K.T.; Harding, H.; Ron, D.; Marks, A.R.; Tabas, I. Role of ERO1 $\alpha$-mediated stimulation of inositol 1, 4, 5-triphosphate receptor activity in endoplasmic reticulum stress-induced apoptosis. J. Cell. Biol. 2009, 186, 783-792. [CrossRef] [PubMed]

52. Li, D.; Chen, J.; Ai, Y.; Gu, X.; Li, L.; Che, D.; Jiang, Z.; Li, L.; Chen, S.; Huang, H.; et al. Estrogen-Related Hormones Induce Apoptosis by Stabilizing Schlafen-12 Protein Turnover. Mol. Cell. 2019. [CrossRef] [PubMed]

53. Fu, Y.; Jin, Y.; Zhao, Y.; Shan, A.; Fang, H.; Shen, J.; Zhou, C.; Yu, H.; Zhou, Y.F.; Wang, X.; et al. Zearalenone induces apoptosis in bovine mammary epithelial cells by activating endoplasmic reticulum stress. J. Dairy Sci. 2019. [CrossRef] [PubMed]

(C) 2019 by the authors. Licensee MDPI, Basel, Switzerland. This article is an open access article distributed under the terms and conditions of the Creative Commons Attribution (CC BY) license (http://creativecommons.org/licenses/by/4.0/). 